\title{
Time-varying linkages between Tourism Receipts and Economic Growth in South Africa
}

\author{
Mehmet Balcilar ${ }^{\mathrm{a}}$, Reneé van Eyden ${ }^{\mathrm{b}, *}$, Roula Inglesi-Lotz ${ }^{\mathrm{b}}$ and Rangan Gupta ${ }^{\mathrm{b}}$
}

\begin{abstract}
The causal link between tourism receipts and GDP has recently become a major focus in the tourism economics literature. Results obtained in recent studies about the causal link appear to be sensitive with respect to the countries analysed, sample period and methodology employed. Considering the sensitivity of the causal link, we use rolling window and time-varying coefficient estimation methods to analyse the parameter stability and Granger causality based on a vector error correction model (VECM). When applied to South Africa for the 1960-2011 period, the findings are as follows: results from the full sample VECM indicate that there is no Granger-causality between tourism receipts and GDP, while the findings from the time-varying coefficients model based on the state-space representation show that tourism receipts have positive-predictive content for GDP for the entire period, with the exception of the period between 1985 and 1990. Full sample time varying causality tests show bidirectional strong causality between tourism receipts and GDP.
\end{abstract}

Keywords: Tourism receipts; economic growth; time-varying causality; time-varying parameter model JEL codes: C32, L83, O40

\footnotetext{
${ }^{\text {a }}$ Department of Economics, Eastern Mediterranean University, Famagusta TR, Northern Cyprus, via Mersin 10, Turkey.

${ }^{\mathrm{b}}$ Department of Economics, University of Pretoria, Private Bag X20, Hatfield, 0028,Pretoria, South Africa.

*Corresponding author. Email: renee.vaneyden@up.ac.za.
} 


\section{Introduction}

Over the past six decades, the tourism sector experienced continued expansion and diversification, becoming one of the largest and fastest-growing economic sectors globally. It is the largest service sector industry in terms of world trade, accounting for 6 per cent of world exports and contributing about 9 per cent to world GDP (UNWTO, 2013). The importance of the tourism sector lies with the fact that it is a labour-intensive sector with the potential to create jobs for relatively unskilled workers. It is also an important earner of foreign exchange - world tourism receipts totalled US\$1,075 billion in 2012. When considering the fact that 35.9 per cent of this amount has been received by emerging economies, the relative importance of the tourism sector in lower income countries is evident. For South Africa in particular, tourism receipts amounted to US\$ 9,994 million or 0.92 per cent of the world total. The importance of the sector for the South African economy has also increased. Before 1994, tourism receipts constituted an average of 2.1 per cent of GDP, while this figure increased to an average of 3.6 per cent of GDP in the post-sanction period, with a contribution to GDP as high as 4.9 per cent in 2003. Within Africa, South Africa has the largest market share on the continent, namely 30 per cent.

It is widely suggested in the literature (e.g. Vanegas and Croes, 2003; Theobald, 2001) that economic growth created by tourism receipts in a country stems from the relationship between exports and economic growth. Specifically, the role of such economic activity, as a promoter of short and long-run economic growth, is investigated by assessing the so-called Tourism Led Growth Hypothesis (TLGH), which is directly derived from the Export-Led Growth Hypothesis (ELGH). The latter postulates that economic growth can be generated, not only by increasing the amount of labour and capital within the economy, but also by expanding exports.

Since tourism receipts are considered part of international services and have a foreign exchange nature, it can be argued that tourism receipts have an export effect (Arslanturk, Balcilar and Ozdemir, 2011). Theobald (2001) also characterizes tourism as an intangible export item. The tourism sector involves a variety of services and professions from other sectors, including: accommodation services, food and beverages, transportation services (passenger transportation and transport equipment rental), cultural services, sports and recreational services, travel services (travel agencies and other reservation services), as well as country-specific tourism characteristic goods and services (including retail trade) (UNWTO, 2010).

The demand for goods and services in the host country will be increased with the rise in tourist arrivals (Dieke, 2000). If the economy visited has the resources to meet the increasing demand as a result of the number of tourists, the spending will remain in the country visited. Foreign exchange surpluses created by tourism activities will have a positive effect on the balance of payments, which is why it is widely acknowledged that tourism in the long run might create economic growth (Balaguer and Jorda, 2002; Croes, 2006). In addition to having a positive impact on the current account, growth in the tourism sector also encourages investments in new infrastructure, stimulates activity in related economic industries, 
creates employment and induces an increase in GDP, thus having a desired effect on the economy concerned (Brohman, 1996; Brida and Pulina, 2010).

The causality relationship between exports and economic growth has been the focus of researchers for a long time (e.g. Balassa, 1988; Ghatak et al. 1997). More recently the causal link between tourism receipts and economic growth, or income, has started to receive a great deal of attention in tourism economics. The first study to test the TLGH was by Balaguer and Cantavella-Jordà (2002) for Spain. A large number of other studies followed, of which the greater majority propose a vector error correction model (VECM) framework. Other time-series techniques employed include the Stock and Watson (1993) dynamic ordinary least squares (DOLS) and the autoregressive distributed lag (ARDL) model developed by Pesaran et al. (2001). A number of panel data studies employed techniques like the Pedroni (2004) approach to test the hypothesis of no cointegration between tourism receipts and economic growth. Hardly any of the studies focussing on tourism and economic growth move beyond the framework of parameter constancy by using rolling window or time-varying coefficients estimation techniques. In a survey of empirical research on the matter, Brida and Pulina (2010) report the findings of 38 studies published between 2002 and 2010. The TLGH is validated for the majority of the countries studied, e.g. Tunisia (Belloumi, 2010), South Africa (Akinboade and Braimoh, 2010), Mauritius (Durbarry, 2004), Antigua and Bermuda (Schubert et al., 2010), Chile (Brida and Risso, 2009), Colombia (Brida et al., 2009), Uruguay (Brida et al., 2008a), Mexico (Brida et al., 2008b), Nicaragua (Croes and Vanegas, 2008), Turkey (Gunduz and Hatemi-J, 2005), Greece (Dritsakis, 2004). A bidirectional Granger causality is found in Malaysia (Lean and Tang, 2009), Taiwan (Kim et al., 2006), Spain (Cortés and Pulina, 2010; Nowak et al., 2007), Malta (Katircioglu, 2009b), Turkey (Ongan and Demiroz, 2005), whereas a unidirectional temporal relationship running from economic development to tourism activity is detected for Korea (Oh, 2005), Fiji, Tonga, Solomon Islands and Papua Guiniea (Narayan et al., 2010), and Cyprus (Katircioglu, 2009a).

In the African context, three studies that apply the VECM methodology to test for Granger causality include Belloumi (2010), Akinboade and Braimoh (2010) and Durbarry (2004) with focus on Tunisia, South Africa and Mauritius, respectively. Belloumi (2010) includes tourism receipts, GDP and real effective exchange rate in a VECM for Tunisia, and finds that tourism receipts Granger causes GDP in the long run. Akinboade and Braimoh (2010) include tourism receipts, GDP, real effective exchange rate and exports in a VECM for South Africa and establish both short and long-run Granger causality running from tourism receipts to GDP. In a study on Mauritius, Durberry (2004) includes tourism receipts, GDP, physical and human capital and exports in a VECM. The findings include the existence of a long-run bidirectional relationship between exports and GDP, while exports Granger causes GDP in the short run.

Lee and Chang (2008) in their panel data analysis concluded that there is a unidirectional causality relationship from tourism to economic growth in OECD countries but a bidirectional relationship in nonOECD countries. Brau et al. (2003) suggested that the smaller the country, the higher the economic growth when the tourism is considered a key factor for the economy. In agreement to this, Eugenio-Martin et al. (2004) found evidence that such a relationship exists but it is stronger for less developed economies but not 
for developed countries and Oh (2005) shows that the relationship is weaker for countries that are not dependent on tourism.

Even within studies for the same country, the results vary when choosing different time periods or methodology. For example, for Turkey, Gunduz and Hatemi-J (2005) find a unidirectional causality from tourism to economic growth using leveraged bootstrap causality tests for the period 1963-2002; Ongan and Demiroz (2005) suggest a bidirectional causality relationship for the period 1980Q1-2004Q2 using the Johansen technique and vector error correction modelling; while Katircioglu (2009c) employing the bounds test and Johansen approach concluded no cointegrating relationship for the period 1960 to 2006.

Arslanturk et al. (2011) attribute these conflicting results to the fact that the existence and direction of the relationship between tourism receipts and economic growth may change through the years, a fact that standard Granger causality tests that are commonly used cannot pick up. They support the argument of Hall et al. $(2009,2010)$ that time-varying estimations can be the solution to the problems of unknown functional forms, specification errors and spurious conclusions, and stress the need for examining the tourismeconomic growth phenomenon for individual countries separately and in a time-varying context. When applying rolling window and time-varying parameter estimation techniques for the period 1963 to 2006 , they show that GDP has no predictive power for tourism receipts in Turkey; however tourism receipts have a positive-predictive content for GDP, but only following the early 1980s, a result that is supportive of the findings of Gunduz and Hatemi-J (2005).

In order to analyse the time-varying linkage between real tourism receipts and real GDP for South Africa for the period 1960 to 2011, we use a time-varying VECM framework to control for structural changes and regime shifts. We support the argument of Arslanturk et al. (2011) that standard Granger causality tests overlook the probable non-constancy of causal relationships and argue the potential nonconstancy of the relationship between tourism and economic performance in the case of South Africa based on the numerous structural changes within the South African economy over the sample period. Moreover, partially due to South Africa's isolation in terms of international trade and tourism between the mid-1980s and early 1990s, limited attention was given to this specific sector. Since 1994 however, the country has improved its tourism position (Saayman and Saayman, 2008) and even more recently, after a number of events that attracted tourists from all over the world such as the Soccer World Cup in 2010. The main contribution of this paper is that it is the first of its kind to examine the South African tourism sector and its relationship with economic growth in a time varying estimation framework. A further innovation on the Arslanturk et al. (2011) paper is that we investigate a potential causal relationship within the VECM context by testing for short-run, long-run and strong causality in a state-space framework. The tests introduces in this study are true time-varying Granger causality tests where all parameters are fully allowed to change with time.

The rest of the paper is organised as follows: Section 2 describes the methodology used, while Section 3 discusses the data used and empirical results of the analysis. The last section concludes. 


\section{Methodology}

Granger non-causality tests are used to determine whether one series significantly forecasts another (Granger, 1969). The null hypothesis generally states the non-existence of one causal relationship for the whole sample. However, a time-varying causal relationship may exist in which case causality might not be applicable in the whole sample; that is to say, a variable might not Granger-cause another variable in some periods and might Granger cause that variable in other periods. When the causal relationship between two variables is not stable and the non-causality is not rejected in a constant parameter model estimated for the full sample, what has been rejected is not clear (Arslanturk et al., 2011). When there are structural changes and policy shifts present, time series might be said not to have a stable single regime.

Against this backdrop our vantage point is to test for the existence of a long-run cointegrating relationship between real tourism receipts and real GDP. If such a relationship is found to exist, a full sample Granger causality test can be carried out within a VECM framework. Consider a bivariate $\operatorname{VECM}(p)$ between tourism receipts $\left(T R_{t}\right)$ and $\operatorname{GDP}\left(G_{t}\right)$ :

$$
\left.\left[\begin{array}{c}
G_{t} \\
T R_{t}
\end{array}\right]=\left[\begin{array}{l}
10 \\
20
\end{array}\right]+\left[\begin{array}{l}
1 \\
2
\end{array}\right] E C T_{t 1}+\sum_{j=1}^{p}\left[\begin{array}{cc}
(j) & (j) \\
11 & 12 \\
(j) & (j) \\
21 & 22
\end{array}\right] \begin{array}{c}
G_{t j} \\
T R_{t j}
\end{array}\right]+\left[\begin{array}{c}
1 t \\
2 t
\end{array}\right]
$$

where $E C T_{t-1}$ is a lagged term derived from the long-run cointegrating relationship between tourism receipts and GDP series, $\varepsilon_{1 t}$ and $\varepsilon_{2 t}$ are uncorrelated disturbance terms with zero mean and finite variance. We estimate the VECM in (1) for the full sample and test the null hypothesis that tourism receipts does not Granger cause GDP $\left(\varphi_{12}^{(1)}=\varphi_{12}^{(2)}=\cdots=\varphi_{12}^{(p)}=0\right)$ and that GDP does not Granger cause tourism receipts $\left(\varphi_{21}^{(1)}=\varphi_{21}^{(2)}=\cdots=\varphi_{21}^{(p)}=0\right)$.

These Granger causality tests, however, assume parameter constancy in the model over time, an assumption, as stated, which may not hold. Salman and Shukur (2004) showed that when the assumption of parameter constancy is violated, Granger causality tests can provide misleading inference about the underlying causal relationship. A model's structure may deviate from assumed stability in numerous ways, leading to many potential alternative specifications against the null hypothesis of stability. Therefore those tests that leave the form of instability unspecified possess desirable properties. Considering the many alternatives for practical problems, researchers require (1) a wide variety of tests to ensure that these tests exhibit power against a conceivable number of alternatives, as some tests indeed possess little power against violations of their assumptions, such as stationarity, no autocorrelation, no outliers, etc., and (2) tools that permit the understanding of the nature of deviations from stability so that the researcher can date the structural change along with the causes. In view of this, in this study, we include a battery of tests that possess power against both specific alternatives and unspecified alternatives, and use rolling and recursive estimation and tests that permits the determination of the form of deviations from stability and also to date the structural changes. 
Firstly, we consider $F$ tests proposed by Andrews (1993) and Andrews and Ploberger (1994) that assume a single structural change under the alternative at an unknown time period. They propose three types of $F$ tests: Sup-F, Ave-F and Exp-F either based on Wald, $L M$, or $L R$ statistics. We implement $L R$ based $F$ tests to test for short-run stability in the VAR model. Secondly, we employ a test to test long-run stability, namely the Nyblom (1989) $L M$ test based on the $M L$ scores, denoted $L_{c}$. Finally, we turn to recursive and rolling fluctuation tests, specifically the modified $M E$ tests proposed by Kuan and Chen (1994) to test long-run parameter stability in the VAR model. We apply the same tests to the long-run relationship between tourism receipts and GDP, estimated by FM-OLS. For a detailed discussion of the different tests, refer to Balcilar et al. (2013).

In conducting rolling estimation, the VECM in (1) is estimated for a time span of 15 years rolling through $t=\tau-14, \tau-13, \ldots, \tau, \tau=15, \ldots, T$. For the recursive estimation, 15 observations are used, and then one period at a time is added to the end of the sample recursively. In order to estimate the order of the VECM in (1), we fit a VECM model to the whole sample period and determine the optimal order using the Akaike information criterion (AIC). For all rolling and recursive VECM estimates, the AIC is also used to determine the lag length.

Given the outcome of various stability tests, we investigate the issue of non-constancy of parameters further. Although the rolling VECM estimates may indicate a time-varying relationship between the tourism receipt and GDP series, the parameter estimates may not be reliable due to the small sample size. Rolling estimation is also not an optimal method to estimate time-varying parameters. In order to estimate the time variation optimally we use a VECM with time-varying coefficients. This approach allows us to overcome the shortcomings of rolling window estimation. Instead of splitting the sample into several subsamples, the time-varying coefficients capture the change in the dynamic relationship and enables exact dating of the transition. In its most general form, the time-varying $\operatorname{VECM}(p)$ model for tourism receipts and GDP series can be written as follows:

$$
\left[\begin{array}{c}
G_{t} \\
T R_{t}
\end{array}\right]=\left[\begin{array}{c}
10, t \\
20, t
\end{array}\right]+\left[\begin{array}{c}
1, t \\
2, t
\end{array}\right] E C T_{t 1}+\sum_{j=1}^{p}\left[\begin{array}{cc}
(j) & (j) \\
11, t & 12, t \\
(j) & (j) \\
21, t & 22, t
\end{array}\right]\left[\begin{array}{c}
G_{t j} \\
T R_{t j}
\end{array}\right]+\left[\begin{array}{c}
1 t \\
2 t
\end{array}\right]
$$

where the error correction coefficients $\gamma_{1, t}$ and $\gamma_{2, t}$ are also time-varying. In the empirical section, using cointegration tests, we show that a long-run relationship between the tourism receipts and GDP series exists. Therefore, the cointegration parameters $\beta_{0}$ and $\beta_{1}$ in $E C T_{t}=G_{t}-\beta_{0}-\beta_{1} T R_{t}$ are modelled as time invariant. In order to write Equation (2) compactly, we define the following matrices:

$$
y_{t}=\left[\begin{array}{c}
G_{t} \\
T R_{t}
\end{array}\right], \quad j, t=\left[\begin{array}{cc}
(j) & (j) \\
11, t & 12, t \\
(j) & (j) \\
21, t & 22, t
\end{array}\right], \quad t_{t}=\left[\begin{array}{l}
1, t \\
2, t
\end{array}\right], \quad 0, t=\left[\begin{array}{r}
10, t \\
20, t
\end{array}\right], \quad t_{t}=\left[\begin{array}{c}
1 t \\
2 t
\end{array}\right]
$$

Then, Equation (2) can be written as

$$
y_{t}=A_{t} Z_{t 1}+{ }_{t}
$$


where $Z_{t}$ is the vector of variables defined as $Z_{t}=\left(1, E C T_{t}, y_{t}, \ldots, y_{t p+1}\right)$ and $A_{t}$ is the matrix of parameters defined as $A_{t}=\left(\begin{array}{lll}0, t & t, & 1, t, \ldots, \\ p, t\end{array}\right)$. Here, $t$ is a $2 \times 1$ vector of white noise with $\operatorname{var}\left({ }_{t}\right)=R$. We assume that each element of $A_{t}$ varies according to a random walk. The random walk specification is flexible, in that it places a minimal restriction on the structure of the time variation. Estimation of the model parameters in Equation (3) can be accomplished by Gaussian quasi-maximum likelihood (Durbin and Koopman, 2001) evaluated using a Kalman filter (e.g. Anderson and Moore, 1979). In order to apply the Kalman filter, the model is represented in the state-space form (see, e.g., Shumway and Stoffer, 2000). Vectorizing both sides of Equation (3), the state-space representation can be written as follows:

$$
\begin{aligned}
y_{t} & =\left(\begin{array}{ll}
Z_{t 1} & I_{2}
\end{array}\right)_{t}+{ }_{t} \\
& =B_{t 1}+v_{t}
\end{aligned}
$$

where $\alpha_{t}$ is the $k$-dimensional state vector defined as ${ }_{t}=\operatorname{vec}\left[\begin{array}{lll}0, t & , & 0, t\end{array}, \ldots,{ }_{p, t}\right]$ with $I_{2}$ denoting a 22 identity matrix, $B$ denoting a $k \quad k$ identity matrix, and $v_{t}$ is a white noise with $\operatorname{var}\left(v_{t}\right)=Q$. We assume that the state noise $v_{t}$ and the observation noise $\varepsilon_{t}$ are contemporaneously correlated with $\operatorname{cov}\left({ }_{t}, v_{t}\right)=S$, and zero otherwise. Let the best linear predictor of $\alpha_{t+1}$ given the data $\left\{y_{1}, \ldots, y_{t}\right\}$ as $\alpha_{t+1}^{t}$, and denote covariance matrix of the prediction error $\eta_{t}=\alpha_{t+1}-\alpha_{t+1}^{t}$ as $P_{t+1}^{t}$. The Kalman filter can be used to obtain the predictors and their covariance matrices successively as new observations become available. The innovation sequence $u_{t}$ is defined as the best linear prediction of $y_{t}$ given the data $\left\{y_{1}, \ldots, y_{t}\right\}$ and given by

$$
u_{t}=y_{t}-\left(Z_{t-1}^{\prime} \otimes I_{2}\right) \alpha_{t}^{t-1}
$$

with the innovation covariance matrix obtained as

$$
{ }_{t}={ }_{t} P_{t}^{t 1}{ }_{t}+R
$$

Since we will be using a bootstrap method, it is more convenient to work with standardized innovations

$$
e_{t}=\Sigma_{t}^{-1 / 2} u_{t}
$$

which guarantees that these innovations have, at least, the same first two moments. The state-pace model in Equation (4) can equivalently be written as

$$
{ }_{t}=F_{t{ }_{t}}+H_{t} e_{t}
$$

where

$$
{ }_{t}=\left[\begin{array}{c}
t \\
{ }_{t+1} \\
y_{t}
\end{array}\right], \quad F_{t}=\left[\begin{array}{c}
I_{k} \\
\left(Z_{t 1}^{\prime} \otimes I_{2}\right)
\end{array}\right], \quad H_{t}=\left[\begin{array}{c}
{\left[P_{t}^{t 1}\left(Z_{t 1}^{\prime} \otimes I_{2}\right)^{\prime}+S\right]_{t}{ }^{1 / 2}} \\
1 / 2 \\
t^{1 / 2}
\end{array}\right] .
$$


Several studies found evidence that sample size must be fairly large before asymptotic results are applicable for the time-varying parameter (TVP) model we consider (Dent and Min, 1978; Ansley and Newbold, 1980). In this paper we use the bootstrap algorithm of Stoffer and Wall (1991) for state-space models. The bootstrap method is preferred for two reasons. First, our sample size is relatively small and bootstrap can approximate the empirical distribution of parameters fairly well (Efron, 1979). Second, it allows us to construct confidence intervals for the estimates of total impact of tourism receipts on GDP ( ${ }_{T R, t}^{*}={ }_{j=1}^{p} \hat{21, t}(j)$ and GDP on tourism receipts $\left({ }_{G, t}^{*}={ }_{j=1}^{p} \underset{12, t}{\wedge(j)}\right)$. After obtaining $B$ bootstrapped estimates of $\psi_{i, t}^{*}, i=T R, G$, the values are ordered and the $100 \kappa$ th value is taken as the lower limit and $100(1-\kappa)$ th value is taken as the upper limit to construct a $(1-2 \kappa) \%$ confidence interval. For a detailed exposition of steps in the bootstrap procedure, refer to Arslanturk et al. (2011).

\section{Data and Empirical Results}

In this section we apply the procedure described above to investigate the time-varying linkages between tourism receipts and GDP using annual data from 1960 to 2011 for South Africa. The data were obtained from the databases of the South African Reserve Bank (SARB) and Global Financial Database (GFD). To investigate these linkages, we use the real tourism receipts and real GDP series. In order to get the real series that we consider, the tourism receipts and GDP series are divided by the consumer price index and GDP deflator, respectively. For purposes of the empirical analysis, both series are expressed in logarithmic form.

Figure 1 illustrates the trend of tourism receipts and GDP for South Africa for the period 1960 to 2011. It can be noted that both variables experienced an upward trend through the examined period. A slowdown is evident, in tourism receipts in particular, from the latter part of the 1970s through the 1980s and until the early 1990s. This period is characterised by political unrest, economic sanctions, the debt standstill agreement and international isolation. These include events like the 1976 Soweto uprising, and the death of political activist Steve Biko in September of 1977. By 1980 the world has decisively turned against South Africa. The declaration of a state of emergency in 1985 was followed by the debt standstill agreement and political, cultural and economic sanctions. Apartheid was however dismantled in a series of negations from 1990 to 1993, starting with the release of Nelson Mandela in February 1990, and finally culminating in the establishment of a democracy in 1994. A particularly steep increase from 1992 onwards is notable in the tourism receipts series while real GDP also grew at more buoyant rates post 1994. Both series show a downturn coinciding and following the recent global financial crisis of 2008/09.

Figure 1. Annual Real GDP and Real Tourism Receipts of South Africa for 1960-2011 


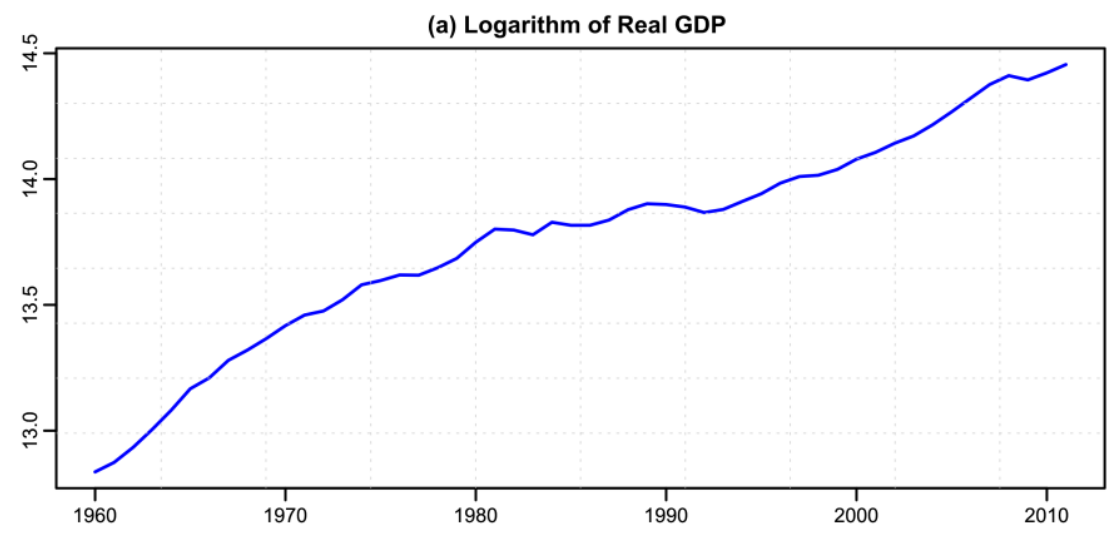

(a) Logarithm of Real Tourism Receipts

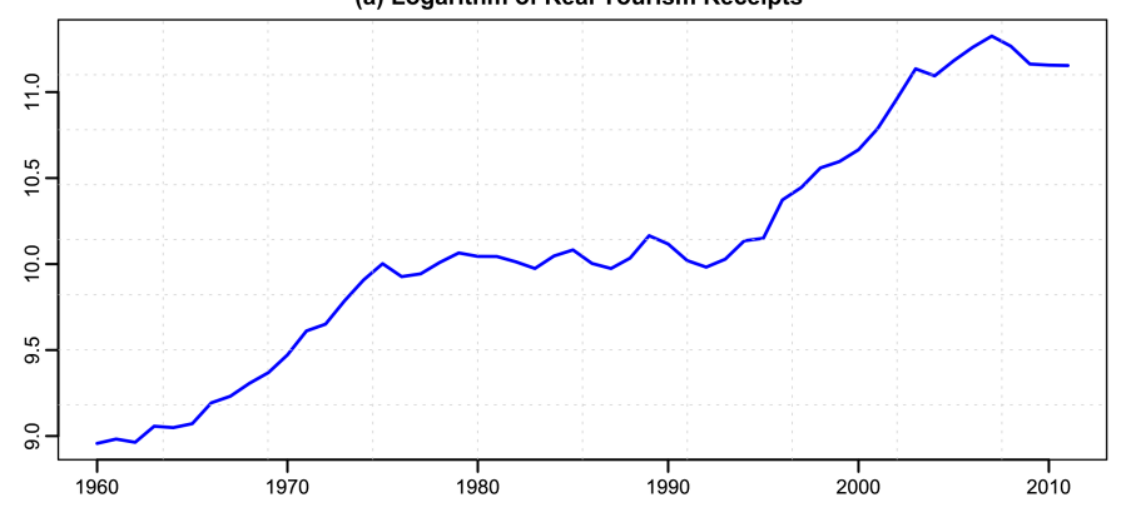

We report the Augmented Dickey-Fuller unit root test of Said and Dickey (1984) and the $M Z_{\alpha}$ unit root test of Ng and Perron (2001) to determine the order of integration of the real tourism receipts and real GDP series. Table 1 reports the results of testing the null of non-stationarity (unit root) against the alternative of stationarity (no unit root). According to the results in Table 1, both the ADF and $M Z_{\alpha}$ tests fail to reject the null hypothesis of non-stationarity for tourism receipts and the GDP. The test results further indicate that the first differences of the series do reject the null of a unit root. Therefore we conclude that both real tourism receipts and real GDP conform to I(1) processes.

\section{Table 1. Unit root test results for Tourism receipts and GDP of South Africa}

\begin{tabular}{lcccc|cccc}
\hline \multicolumn{5}{c}{ Level } & \multicolumn{4}{c}{ First Differences } \\
\hline Series & $\mathrm{ADF}_{\mu}{ }^{\mathrm{a}}$ & $\mathrm{ADF}_{\tau}^{\mathrm{b}}$ & $\mathrm{MZ}_{\alpha}^{\mathrm{c}}$ & $\mathrm{MZ}_{\alpha}{ }^{\mathrm{d}}$ & $\mathrm{ADF}_{\mu}{ }^{\mathrm{a}}$ & $\mathrm{ADF}_{\tau}^{\mathrm{b}}$ & $\mathrm{MZ}_{\alpha}^{\mathrm{c}}$ & $\mathrm{MZ}_{\alpha}{ }^{\mathrm{d}}$ \\
\hline Tourism receipts & $-0.92(1)$ & $-1.82(1)$ & 1.46 & -5.66 & $-3.75^{* * * *}(1)$ & $-3.73^{* * *}(1)$ & $-22.07^{* * * *}$ & $-23.38^{* * *}$ \\
GDP & $-0.83(1)$ & $-2.39(1)$ & 1.84 & -1.47 & $-4.36^{*}(1)$ & $-4.27^{* * *}(1)$ & $-18.77^{* * *}$ & $-20.17^{* * *}$ \\
\hline
\end{tabular}

Notes: $* * * * * *$ indicate significance at the 10,5 and 1 per cent levels, respectively.

${ }^{\text {a }}$ Test allows for a constant; one-sided test of the null hypothesis that the variable has a unit root; $10,5,1$ per cent significance critical value equals $-2.58,-2.89,-3.51$, respectively.

${ }^{\mathrm{b}}$ Test allows for a constant and a linear trend; one-sided test of the null hypothesis that the variable has a unit root; 10,5 , 1 per cent critical value equals $-3.15,-3.45,-4.04$, respectively.

${ }^{\mathrm{c}}$ Test allows for a constant; one-sided test of the null hypothesis that the variable has a unit root; $10,5,1$ per cent critical values equals $-5.7,-$ $8.1,-13.8$, respectively.

${ }^{\mathrm{d}}$ Test allows for a constant and a linear trend; one-sided test of the null hypothesis that the variable has a unit root; 10,5 , 1 per cent critical values equals $-14.2,-17.3,-23.8$, respectively. 
Because an error correction term is an essential part of Granger causality analysis, next we test for a common stochastic trend, which implies the existence of a cointegrating relationship between GDP and tourism receipts. According to Granger (1988), if the causality tests do not incorporate an error correction term, they may lead to incorrect conclusions. Since both series contain a stochastic trend, a common stochastic trend is likely to occur; that is the series may be cointegrated. We use Johansen's (1991) maximum likelihood method to examine whether or not the tourism receipt and GDP series are cointegrated. Table 2 reports the Johansen cointegration trace test statistic. The test results indicate that the null hypothesis of no cointegration between the tourism receipts and GDP series is rejected at the 5 per cent significance level.

Table 2. Cointegration test results for tourism receipts and GDP of South Africa

\begin{tabular}{lcr}
\hline Variables & Null Hypothesis a and $b$ & Trace Test \\
\hline Tourism receipts and GDP & $r=0$ & $28.43^{\dagger}$ \\
& $r \leq 1$ & 3.08 \\
\hline
\end{tabular}

Note: $\uparrow$ and $*$ indicate significance at the 5 and 1 per cent levels, respectively.

One-sided test of the null hypothesis that the variables are not cointegrated; reported critical values are the Osterwald-Lenum (1992) critical values; 5 and 1 per cent critical values equal 9.24 and 12.97 for $r \leq 1$, respectively; and 19.96 and 24.60 for $r=0$, respectively.

Considering the cointegration between the tourism receipts and GDP series, that is that tourism receipts and GDP maintain a long-run relationship in levels, there should be causality at least in one direction (Engle and Granger, 1987). In order to examine the type of causality between the series, we first perform a full sample Granger-causality test. We use the Akaike information criterion (AIC) for determining the optimal number of lags in the VAR model. Starting with $p=1$, we sequentially increase the lag of VAR model up to ten, and select the lag order with minimum AIC. As suggested by AIC, the optimal lag order is $1 .^{1}$ Next a VECM as specified in (1) is used for the full sample to test the null hypotheses that tourism receipts does not Granger cause GDP $\left({ }_{12}^{(1)}=0\right)$ and that GDP does not Granger cause tourism receipts ${ }^{2}\left(\begin{array}{l}(1) \\ 21\end{array}=0\right)$.

Table 3. Pair-wise Granger-causality test results between tourism receipts and GDP series in a VECM model

\begin{tabular}{ccccc}
\hline & \multicolumn{3}{c}{$\mathrm{H}_{0}$ : Tourism receipt does not Granger cause GDP } & $\mathrm{H}_{0}$ : GDP does not Granger cause tourism receipt \\
\cline { 2 - 5 } Lags & $F$-Statistic & $p$-value & $F$-Statistic & $p$-value \\
\hline 1 & 2.024 & 0.143 & 1.745 & 0.186 \\
\hline
\end{tabular}

Notes: Granger causality tests are for the joint non-causality both in the short- and long run

$*$ denotes significance at the 5 per cent significance level.

\footnotetext{
${ }^{1}$ The lag order $p$ we refer to relates to the VECM model and the order of the level VAR is $p+1$.

2 These restrictions test for the short-run causality. The long-run causality can be tested by zero restrictions on the coefficients relating to the error-correction term.
} 
The results show that we fail to reject the null hypothesis that tourism receipt does not Granger cause GDP and vice-versa at any of the conventional significance levels. These findings show that there is no short-run Granger causality from tourism receipts to GDP or from GDP to tourism receipts when a full sample Granger-causality test is performed.

We now turn to examining the stability of the estimated parameters in the long-run equation as well as the VAR framework. Structural changes may shift parameter values and the pattern of the no causal relationship may change over time. Granger causality tests will show sensitivity to sample period and order of the VAR model, if the parameters are temporally instable. The results of cointegration and Granger causality tests based on the full sample also become invalid with structural breaks because these tests assume parameter stability.

\section{Full-sample parameter stability}

Various tests exist to examine temporal stability of VAR models (e.g. Hansen, 1992b; Andrews, 1993; Andrews and Ploberger, 1994). Although we can apply these tests in a straightforward way for stationary models, the variables in our model are non-stationary and cointegrated. We need to accommodate the possibility of this integration (cointegration) property because in a cointegrated VAR, the variables form a vector error correction model (VECM). Thus we need to investigate the stability of both the long-run cointegration and the short-run dynamic adjustment parameters. If the long-run or cointegration parameters prove to be stable, then the model exhibits long-run stability. Additionally, if the short-run parameters are also stable, then the model exhibits full structural stability.

Since the estimators of cointegration parameters are superconsistent we can split the parameter stability testing procedure into two steps. First, we test the stability of the cointegration parameters. Second, if long-run parameters prove stable, then we can test the stability of the short-run parameters. To examine the stability of cointegration parameters, we use the $L_{c}$ test of Nyblom (1989) and Hansen (1992a). This Nyblom-Hansen statistic tests for parameter constancy against the alternative hypothesis that the parameters follow a random walk process and, therefore are time-varying, since the first two moments of a random walk are time dependent. Next we use the Sup-F, Mean-F, and Exp-F tests developed by Andrews (1993) and Andrews and Ploberger (1994) to investigate the stability of the short-run parameters. We compute these tests from the sequence of $L R$ statistics that tests constant parameters against the alternative of a one-time structural change at each possible point of time in the full sample. These tests exhibit asymptotic non-standard distributions and Andrews (1993) and Andrews and Ploberger (1994) report the critical values. To avoid the use of asymptotic distributions, however, we calculate the critical values using the parametric bootstrap procedure.

The outcome of these tests for parameter constancy to derive inference on the temporal stability of the coefficients of the VAR model for tourism receipts and GDP is presented in Table 4. Bootstrap $p$-values come from a bootstrap approximation to the null distribution of the test statistics, constructed by means of Monte-Carlo simulation using 2,000 samples generated from a VAR model with constant parameters. We 
calculate the $L_{c}$ test for each equation separately using the FM-OLS estimator of Phillips and Hansen (1990). The Sup-F, Mean-F and Exp-F tests require trimming at the ends of the sample. Following Andrews (1993), we trim 15 per cent from both ends and calculate these tests for the fraction of the sample in $[0.15,0.85]$.

The results for the $L_{c}$ test of stability of the cointegration parameters indicate that both the tourism receipts and GDP equations exhibit stable long-run parameters at the 5 per cent significance level. That is, we find evidence of cointegration. There is also evidence of parameter constancy, or stability, in the unrestricted VAR(2) system.

Next, we consider the short-run parameter stability, using the Sup-F, Mean-F and Exp-F test result, also reported in Table 4. The Sup-F statistics test parameter constancy against a one-time sharp shift in parameters. On the other hand the Mean-F and Exp-F, which assumes that parameters follow a martingale process, test for gradual shifting in the regime. Both the Mean-F and Exp-F statistics test the overall constancy of the parameters (i.e. they investigate whether the underlying relationship among the variables stays stable over time). In addition, Andrews and Ploberger (1994) show that the Mean-F and Exp-F are both optimal tests. The results reported for the sequential Sup-F, Mean-F and Exp-F suggest that significant evidence of parameter non-constancy exists in the tourism receipts and GDP equations, as well as in the entire VAR system at the 5 per cent level, except for the Mean-F test for the GDP equation.

In sum, the evidence obtained from the parameter stability tests indicate that the cointegrated VAR model does exhibit constant long-run parameters, whereas the short-run dynamics of the model show parameter instability. The $L_{c}$, Sup-F, Mean-F and Exp-F tests prove consistent in this regard.

Table 4. Parameter Stability Tests in VAR(2) Model

\begin{tabular}{lcccccc}
\hline & \multicolumn{2}{c}{ Tourism Receipts Equation } & \multicolumn{2}{c}{ Real GDP Equation } & \multicolumn{2}{c}{ VAR(2) System } \\
\cline { 2 - 7 } & Statistics & $\begin{array}{c}\text { Bootstrap } \\
\boldsymbol{p} \text {-value }\end{array}$ & Statistics & $\begin{array}{c}\text { Bootstrap } \\
\boldsymbol{p} \text {-value }\end{array}$ & Statistics & $\begin{array}{c}\text { Bootstrap } \\
\boldsymbol{p} \text {-value }\end{array}$ \\
\hline Mean-F & 23.11 & $<0.01$ & 6.00 & 0.26 & 10.73 & 0.04 \\
Exp- $\boldsymbol{F}$ & 53.48 & $<0.01$ & 8.00 & $<0.01$ & 8.12 & 0.02 \\
Sup- $\boldsymbol{F}$ & 114.19 & $<0.01$ & 22.77 & $<0.01$ & 22.74 & 0.02 \\
$\boldsymbol{L}_{\boldsymbol{c}}$ & 0.33 & 0.75 & 0.44 & 0.67 & 0.69 & 0.57 \\
Rolling $\boldsymbol{L}_{2}$ norm & 0.90 & 0.33 & 1.16 & 0.15 & 2.67 & 0.01 \\
Recursive $\boldsymbol{L}_{2}$ norm & 1.93 & 0.03 & 0.94 & 0.31 & 2.50 & $<0.01$ \\
\hline
\end{tabular}

Notes: We calculate $p$-values using 2,000 bootstrap repetitions.

To allow for a set of alternative tests, we also estimate the cointegration equation between tourism receipts and real GDP as follows: 


$$
G D P_{t}=\alpha+\beta^{*} T R_{t}+\varepsilon_{t}
$$

where GDP denotes real GDP and $T R$ denotes tourism receipts. We estimate the parameters in equation (9) using the FM-OLS estimator. Table 5 reports the results of the various parameter stability tests. The Nyblom-Hansen $L_{c}$ test cannot reject the null of constant parameters at any reasonable level. Similarly, the Mean- $F$ and Exp- $F$ tests cannot reject the null hypothesis of unchanging parameters in the cointegration equation. In other words, we do not find evidence of gradual shifting of the parameters of the cointegration equation. The Sup-F test, however, suggests a one-time shift in the cointegration relationship.

Table 5. Parameter Stability Tests in Long-Run Relationship FM-OLS

\begin{tabular}{lcccccc}
\hline & Mean-F & Exp-F & Sup-F & $\boldsymbol{L}_{\boldsymbol{c}}$ & $\begin{array}{c}\text { Rolling } \boldsymbol{L}_{2} \\
\text { norm }\end{array}$ & $\begin{array}{c}\text { Recursive } \\
\boldsymbol{L}_{\mathbf{2}} \text { norm }\end{array}$ \\
\hline Equation: $\boldsymbol{G D P}=\alpha+\boldsymbol{\beta}^{*} \boldsymbol{T R}$ & 42.22 & 35.92 & 78.51 & 0.27 & 3.80 & 2.72 \\
Bootstrap $\boldsymbol{p}$ value & 0.92 & 0.77 & $<0.01$ & 0.53 & $<0.01$ & $<0.01$ \\
\hline Not & & & & &
\end{tabular}

Notes: We calculate $p$-value using 2,000 bootstrap repetitions.

\section{Recursive and Rolling Window Parameter Stability}

Since the parameter constancy tests point to structural change, we estimate the VAR model using recursive and rolling window regression techniques. The recursive estimator starts with a benchmark sample period and then adds one observation at a time keeping all observations in prior samples so that the sample size grows by one with each iteration. The rolling-window estimator, also known as fixed-window estimator, alters the fixed length benchmark sample by moving sequentially from the beginning to the end of sample by adding one observation from the forward direction and dropping one from the end. Assume that each rolling subsample includes 15 annual observations (i.e., the window size is equal to 15). In each step for the recursive and moving window models, we determine a VAR model using the AIC to choose the lag length and perform the Granger causality tests using the residual based (RB) bootstrap method on each subsample. This provides us with a sequence of 36 causality tests instead of just one. The recursive and rolling estimations that we adopt are justified for a number of reasons. First, recursive and rolling estimations allow the relationship between the variables to evolve through time. Second, the presence of structural changes introduces instability across different subsamples and recursive and rolling estimations conveniently capture this; in our case, by considering a sequence of 36 different subsamples (starting with the benchmark sample from 1962 to 1976). The rolling window uses a 15-year fixed window.

For the rolling estimations, the window size is an important choice parameter. Indeed, the window size controls the number of observations covered in each subsample and determines the number of rolling estimates, since a larger window size reduces the number of observations available for estimation. More importantly, the window size controls the precision and representativeness of the subsample estimates. A large window size increases the precision of estimates, but may reduce the representativeness, particularly, in the presence of heterogeneity. On the contrary, a small window size will reduce heterogeneity and 
increase representativeness of parameters, but it may increase the standard error of estimates, which reduces accuracy. Therefore, the choice of the window size should achieve a balance of not too large or too small, thus, balancing the trade-off between accuracy and representativeness. We follow Koutris et al. (2008) and Balcilar et al. (2013) and use a rolling window of small size (i.e., 15 annual observations) to guard against heterogeneity. Our choice of small window size may lead to imprecise estimates. Therefore, we apply the bootstrap technique to each subsample estimation in order to obtain more precise parameter estimates and tests.

No strict criterion exists for selecting the window size in rolling window estimation. Pesaran and Timmerman (2005) examine the window size under structural change in terms of root mean square error. They show that optimal window size depends on persistence and size of the break. Their Monte Carlo simulations shows that we can minimize the bias in autoregressive (AR) parameters with window sizes as low as 20 when frequent breaks exist. In determining the window size, we need to balance between two conflicting demands. First, the accuracy of parameter estimates depends on the degree of freedom and requires a larger window size for higher accuracy. Second, the presence of multiple regime shifts increases the probability of including some of these multiple shifts in the windowed sample. In order to reduce the risk of including multiple shifts in the subsamples, the window size should be small. Based on the simulation results in Pesaran and Timmerman (2005) we use a window size of 15 (this excludes the observations required for lags and hence is the actual number of observations in the VAR).

First consider the VAR(2) system. The recursive $M E-L_{2}$ statistic is reported in the last row in Table 4. Only the GDP equation shows evidence of parameter stability, while the tourism receipt equation as well as the $\operatorname{VAR}(2)$ system show evidence of parameter instability, at the 5 per cent and 1 per cent levels of significance, respectively. Figure 2(a) provides a sample-by-sample picture of the $M E-L_{2}$ test statistic for the individual equations as well as for the VAR system. ${ }^{3}$. The figure indicates several periods of time when we can reject the null of parameter stability at the 5 per cent level, namely 1975 to 1976 (coinciding with political events such as the Soweto uprising and the death of political activist, Steve Biko), a relative long period from 1983 to 1998 (which includes the debt standstill agreement and a period of sanctions of a political, economic and cultural nature) and 2001 (a period marked by volatility in the South African currency market). Instability in these selective periods also reflects proximately instability in the GDP equation, even though the $M E-L_{2}$ test indicates parameter stability overall.

Figure 2. Stability Tests for VAR(2) Model

\footnotetext{
${ }^{3}$ Figure 2 only reports the significance level and mean $L_{2}$ norm test for the VAR system and not for the individual equations. The mean value is indicated with a dotted line, while the 5 per cent significance level is indicated a solid horizontal line.
} 


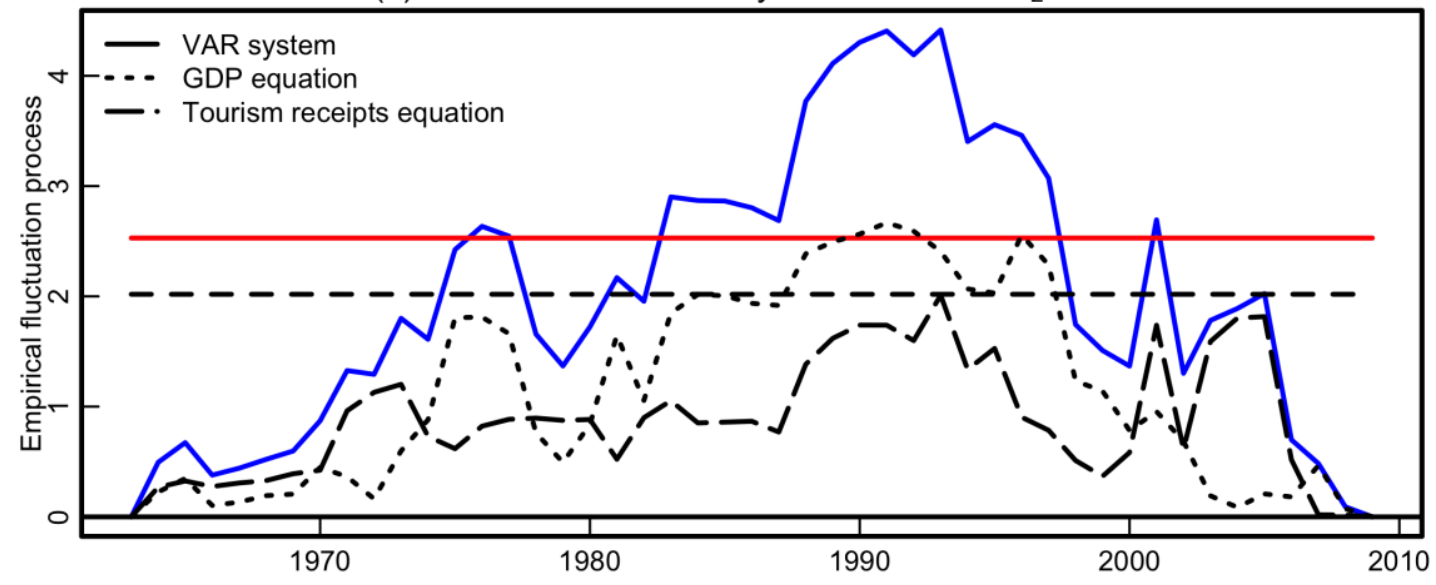

(b) Rolling VAR stability tests test with mean $L_{2}$ norm

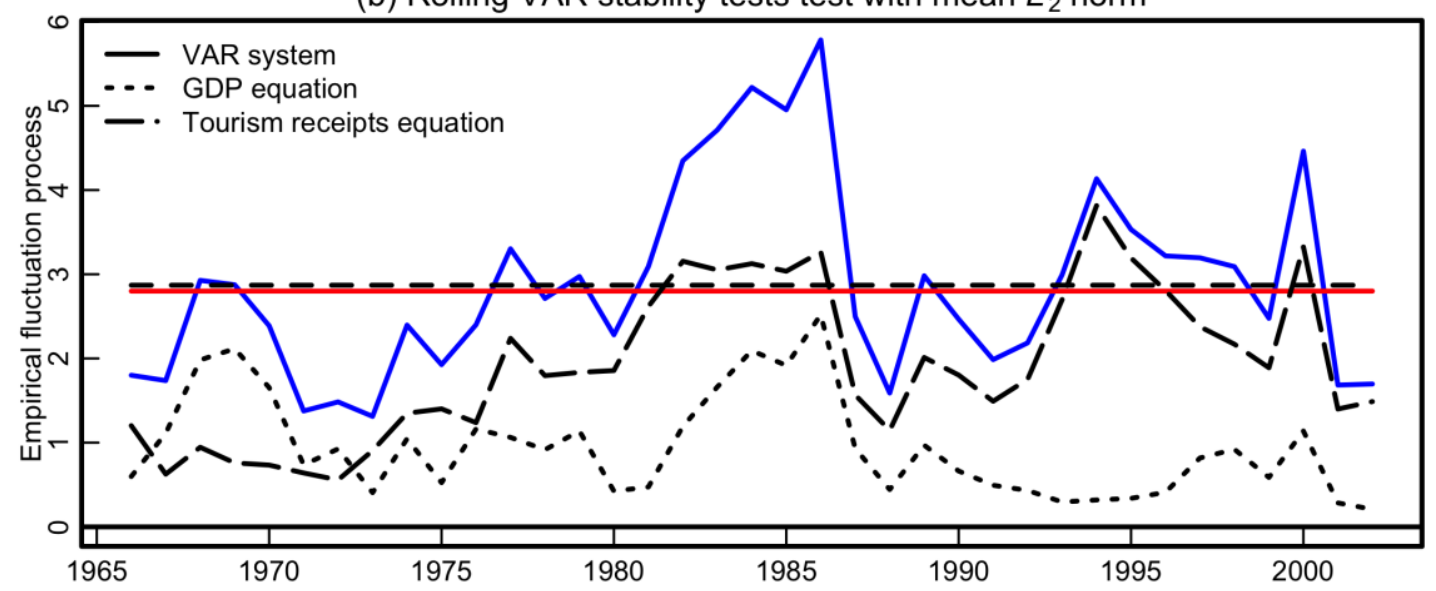

Notes: Rolling window size is 15 observations, approximately $30 \%$ of the observations. Rolling estimates are centered at [h/2] where $h$ is the window size and $[a]$ is the integer part of $a . F$ tests use 15 per cent trimming from both ends.

The rolling $M E-L_{2}$ test statistic in the second last row in Table 4 implies that both the tourism receipt and GDP equations exhibit parameter stability, while the $M E-L_{2}$ test for the VAR system implies parameter instability at the 1 per cent level. Figure 2(b) indicates that we reject the null hypothesis of stable parameters for a number of shorter periods, namely 1976 and 1979 and from 1980 to 1987, 1990, 1993 to 1998 and again in 2001. Instability in all periods reflects instability in the tourism receipt equation.Finally, consider the long-run cointegrating relationship. Table 5 reports the Sup-F, Mean-F, Exp-F and $L_{c}$ test results. All tests, with the exception of the Sup-F test, support parameter stability in the long run. For both the rolling and recursive specifications however, we find that the parameters of the long-run trend equation exhibit parameter instability at the 1 per cent level.

For the recursive regressions, Figure 3(a) plots the sample by sample $M E-L_{2}$ test statistic for the long-run equation. The $M E-L_{2}$ test statistic indicates that the parameters do not remain stable over the entire period. In addition, the statistics reported suggest that parameter instability begins shortly after the beginning of the full sample and ends just before the end, that is, the test suggests instability from 1962 to 
2005. For the rolling regressions, Figure 3(b) plots the $M E-L_{2}$ statistics. The statistics reported for each subsample over the entire period, suggests parameter instability between 1984 and 2003.

Figure 3. Stability Tests for the Long-Run Relationship based on FM-OLS Estimation

(a) Recursive long-run FM-OLS stability test with mean $L_{2}$ norm

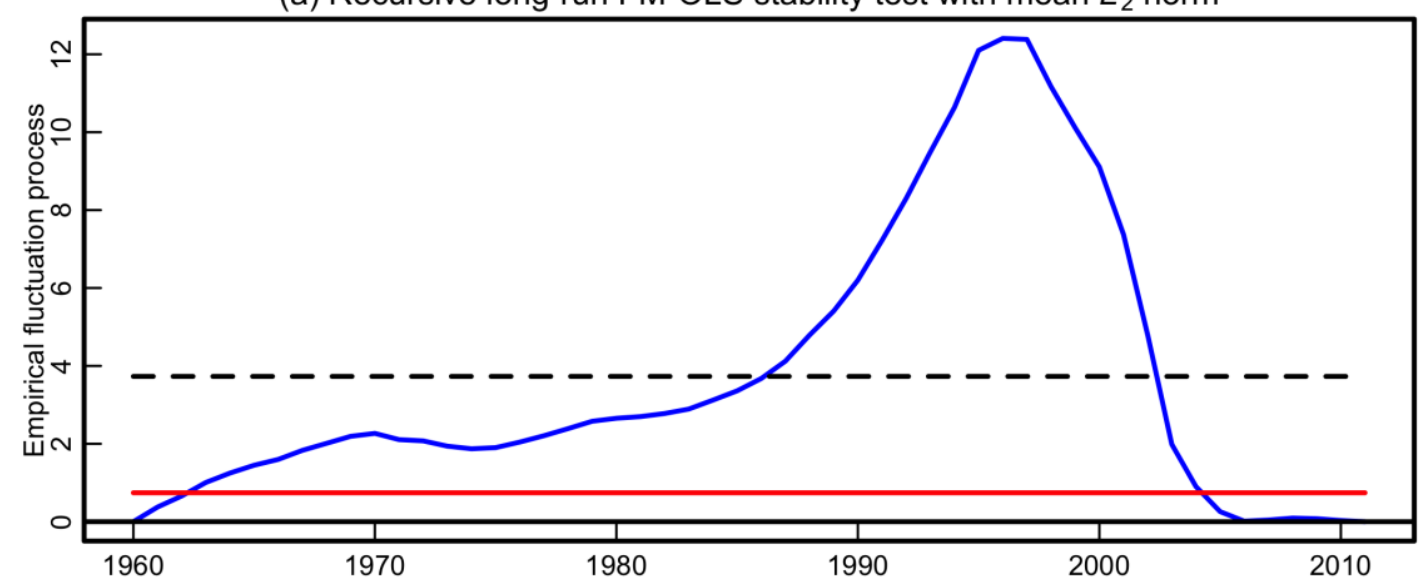

(b) Rolling long-run FM-OLS stability tests test with mean $L_{2}$ norm

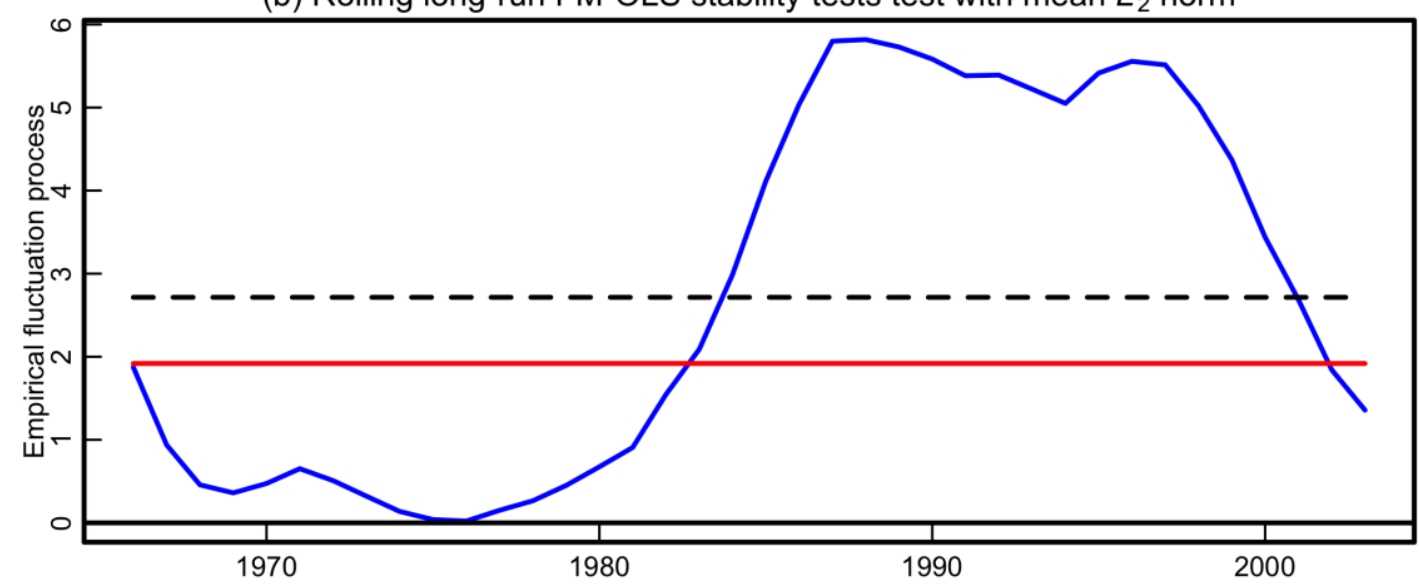

We next proceed to carry out Granger non-causality tests in a time-varying parameter VECM context. We test 7 different hypotheses as set out in Table 6, namely that of constant parameters in the VECM, short-run causality, long-run causality, and strong causality, which implies both short and long-run causality. The associated restrictions in the VECM and state space forms are also indicated for all 7 hypotheses. In table 7 , information criteria and log likelihood values for the unrestricted, full sample model is compared to a number of different restricted models. 
Table 6. Testable Full-Sample Non-causality Hypotheses and Restrictions in TVP-VECM Model

\begin{tabular}{|c|c|c|c|}
\hline \multicolumn{2}{|l|}{ Hypothesis } & Restrictions in VECM form & Restrictions in SS form \\
\hline $\mathrm{H}_{01}$ : Constant para & ameters & $i, t={ }_{i}, \quad(k)={ }_{i j, t}^{(k)}, \quad i, j=1,2$ & $Q=0$ \\
\hline \multicolumn{4}{|l|}{ Short-run causality } \\
\hline $\mathrm{H}_{02}: \mathrm{T}$. receipts $=$ & GDP & ${ }_{12, t}^{(k)}=0$ & $q_{j_{1} j_{1}}=0, \quad b_{j_{1} j_{1}}=0$ \\
\hline $\mathrm{H}_{03}: \mathrm{GDP}=$ & T. receipts & ${ }_{21, t}^{(k)}=0$ & $q_{j_{2} j_{2}}=0, \quad b_{j_{2} j_{2}}=0$ \\
\hline \multicolumn{4}{|l|}{ Long-run causality } \\
\hline $\mathrm{H}_{04}: \mathrm{T}$. receipts $=$ & GDP & ${ }_{1, t}=0$ & $q_{j_{3} j_{3}}=0, \quad b_{j_{3} j_{3}}=0$ \\
\hline $\mathrm{H}_{05}: \mathrm{GDP}=$ & T. receipts & ${ }_{2, t}=0$ & $q_{j_{j_{4} j_{4}}}=0, \quad b_{j_{4} j_{4}}=0$ \\
\hline \multicolumn{4}{|l|}{ Strong causality } \\
\hline $\mathrm{H}_{06}: \mathrm{T}$. receipts $=$ & GDP & ${ }_{1, t}=0, \quad{ }_{12, t}^{(k)}=0$ & $q_{j_{j_{1} j_{1}}}=q_{j_{3} j_{3}}=0, \quad b_{j_{j_{1}}}=b_{j_{j_{3} j_{3}}}=0$ \\
\hline $\mathrm{H}_{07}: \mathrm{GDP}=$ & T. receipts & ${ }_{2, t}=0, \quad{ }_{21, t}^{(k)}=0$ & $q_{j_{2} j_{2}}=q_{j_{j j_{4}}}=0, \quad b_{j_{2} j_{2}}=b_{j_{j_{4} j_{4}}}=0$ \\
\hline
\end{tabular}

Note: $X=\quad Y$ means variable $X$ does not Granger cause variable $Y . q_{i j}$ is the element in $i$ th row and $j$ th column of $Q$, similarly $b_{i j}$ is the element in $i$ th row and $j$ th column of $B$.

Table 7. Information Criteria and Log Likelihood of Estimated State Space Models

\begin{tabular}{|c|c|c|c|c|}
\hline Model under restriction: & Restriction & $\mathrm{AIC}$ & $\mathrm{AICc}$ & $\log L$ \\
\hline Full model, Eq. 4 & None & -260.30 & -208.30 & 169.15 \\
\hline $\mathrm{H}_{01}$ : Constant parameters & ${ }_{i, t}={ }_{i,}, \quad{ }_{i j, t}^{(k)}={ }_{i j}^{(k)}, \quad i, j=1,2$ & -220.15 & -219.90 & 113.08 \\
\hline $\mathrm{H}_{02}:$ T. receipts $=$ & ${ }_{12, t}^{(k)}=0$ & -186.95 & -157.77 & 124.47 \\
\hline $\mathrm{H}_{03}: \mathrm{GDP}=$ & ${ }_{21, t}^{(k)}=0$ & -177.40 & -148.22 & 119.70 \\
\hline $\mathrm{H}_{04}: \mathrm{T}$. receipts $=$ & ${ }_{1, t}=0$ & -178.55 & -149.37 & 120.27 \\
\hline $\mathrm{H}_{05}: \mathrm{GDP}=\quad \mathrm{T}$. receipt & ${ }_{2, t}=0$ & -181.42 & -152.25 & 121.71 \\
\hline $\mathrm{H}_{06}: \mathrm{T}$. receipts $=\quad$ GDP & $\begin{array}{ll}1, t & =0, \quad{ }^{(k)} \\
& 12, t\end{array}=0$ & -212.21 & -196.21 & 130.11 \\
\hline $\mathrm{H}_{07}: \mathrm{GDP}=\quad \mathrm{T}$. receipts & ${ }_{2, t}=0, \quad{ }_{21, t}^{(k)}=0$ & -209.55 & -193.55 & 128.77 \\
\hline
\end{tabular}

Notes: See Table 6 for definition of restricted models. AIC is the Akaike information criterion, AICc is the small sample corrected Akaike information criterion of Hurvich and Tsai (1989). $\log L$ is the value of the log likelihood.

Table 8 reports full-sample bootstrap Granger causality tests under the TVP-VECM specification in equation (4). Firstly, the rejection of the null of constant parameters is supportive of earlier stability test results. We reject the null that the tourism receipts variable does not Granger cause GDP in the short run, and vice versa. We also reject the null of long-run non-causality from tourism receipts to GDP at the 1 per cent level, implying that tourism receipts have predictive power for GDP. From Figure 4(b) it is evident that this predictive content is statistically significant from the 1990s onwards, at a significance level of 20 per cent. The speed of adjustment coefficient of the GDP equation, ranging between -0.09 and -0.10 , is 
indicative of a fairly slow speed of adjustment after deviation from equilibrium due to an external shock (see Figure 4(a)). The coefficient is significant at the 5 per cent level for the entire period, indicating that tourism receipts have long-run predictive content for GDP over the sample period.

Moreover, we also reject the restriction $\quad{ }_{2, t}=0$ at the 1 per cent level, this rejection imply long-run causality from GDP to tourism receipts. Therefore, we conclude that both tourism receipts and GDP behave weakly endogenously with respect to each other and there is long-run bidirectional causality between the two variables..

Table 8. Full Sample Bootstrap Granger Causality Tests Under TVP-VECM

\begin{tabular}{|c|c|c|c|c|}
\hline Hypothesis & Restrictions in SS form & \# restriction & LR test & $\begin{array}{c}\text { Bootstrap } \\
p \text {-value }\end{array}$ \\
\hline $\mathrm{H}_{01}$ : Constant parameters & $Q=0$ & 36 & 112.15 & $<0.01$ \\
\hline \multicolumn{5}{|l|}{ Short-run causality } \\
\hline $\mathrm{H}_{02}: \mathrm{T}$. receipts $=$ & $q_{j_{1} j_{1}}=0, \quad b_{j_{1} j_{1}}=0$ & 2 & 89.36 & $<0.01$ \\
\hline $\mathrm{H}_{03}: \mathrm{GDP}=$ & $q_{j_{2} j_{2}}=0, \quad b_{j_{2} j_{2}}=0$ & 2 & 98.91 & $<0.01$ \\
\hline \multicolumn{5}{|l|}{ Long-run causality } \\
\hline $\mathrm{H}_{04}:$ T. receipts $=$ & $q_{j_{3} j_{3}}=0, \quad b_{j_{3} j_{3}}=0$ & 2 & 97.76 & $<0.01$ \\
\hline $\mathrm{H}_{05}: \mathrm{GDP}=$ & $q_{j_{4} j_{4}}=0, \quad b_{j_{4} j_{4}}=0$ & 2 & 96.88 & $<0.01$ \\
\hline \multicolumn{5}{|l|}{ Strong causality } \\
\hline $\mathrm{H}_{06}: \mathrm{T}$. receipts $=$ & $q_{j_{1} j_{1}}=q_{j_{3} j_{3}}=0, \quad b_{j_{1} j_{1}}=b_{j_{3} j_{3}}=0$ & 4 & 78.09 & $<0.01$ \\
\hline $\mathrm{H}_{07}: \mathrm{GDP}=\quad \mathrm{T}$. receipts & $q_{j_{2} j_{2}}=q_{j_{4} j_{4}}=0, \quad b_{j_{2} j_{2}}=b_{j_{j_{4} j_{4}}}=0$ & 4 & 80.76 & $<0.01$ \\
\hline
\end{tabular}

Notes: See Table 6 for definition of restricted models. $p$-values are obtained with 2000 bootstrap simulations.

Then finally, when testing the hypotheses of strong causality, we reject the null that tourism receipts does not Granger cause GDP at the 1 per cent level, to conclude strong causality running from tourism receipts to GDP. Tourism receipts therefore have predictive content for GDP both in the short and long run. Since both GDP and tourism receipts are not weakly exogenous, rejection of the null of Granger non-causality hypotheses in Table 8 imply that tourism receipts and GDP have predictive power for each other both in the short- and long-run. 
Figure 4. Adjustment Speed in GDP Equation and Test for the Long-Run Causality from Tourism Receipts to GDP

(a) Estimates of $\gamma_{1, t}$ and $95 \%$ bootstrap bounds

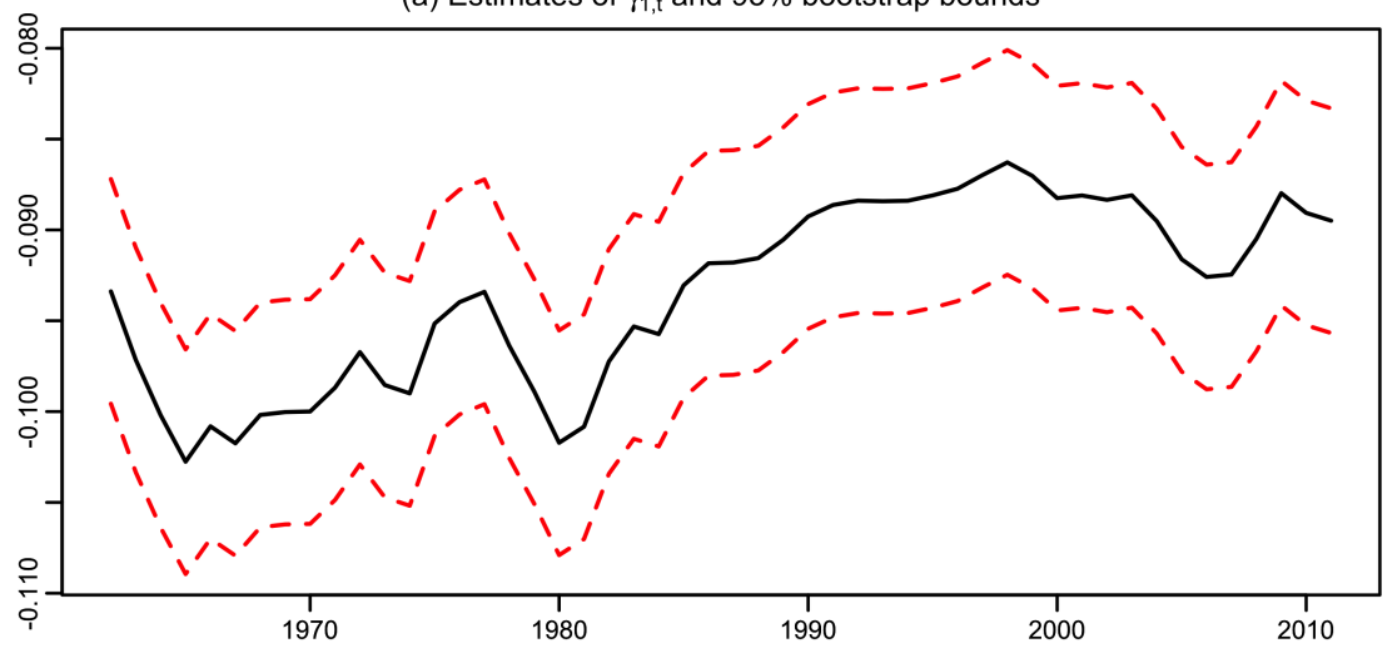

(b) p-value of $H_{0}: \gamma_{1, t}=0$

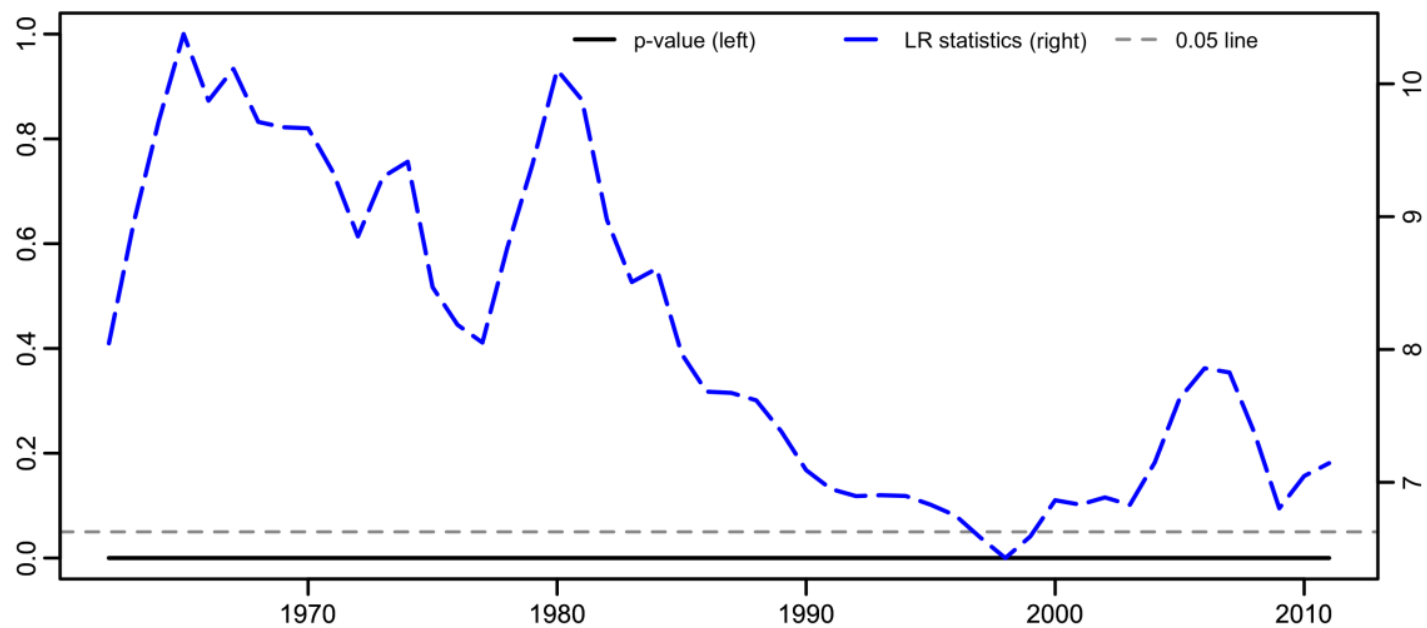

Notes: Parameters are estimated by maximum likelihood of the state-space model. The LR tests are calculated sequentially for $t=1,2, \ldots, T$ using the method in Doran (1992). The $p$-values are obtained using 2000 bootstraps. 
Figure 5. Adjustment Speed in Tourism Receipts Equation and Test for the Long-Run Causality from GDP to Tourism Receipts

(a) Estimates of $\gamma_{2, t}$ and $95 \%$ bootstrap bounds

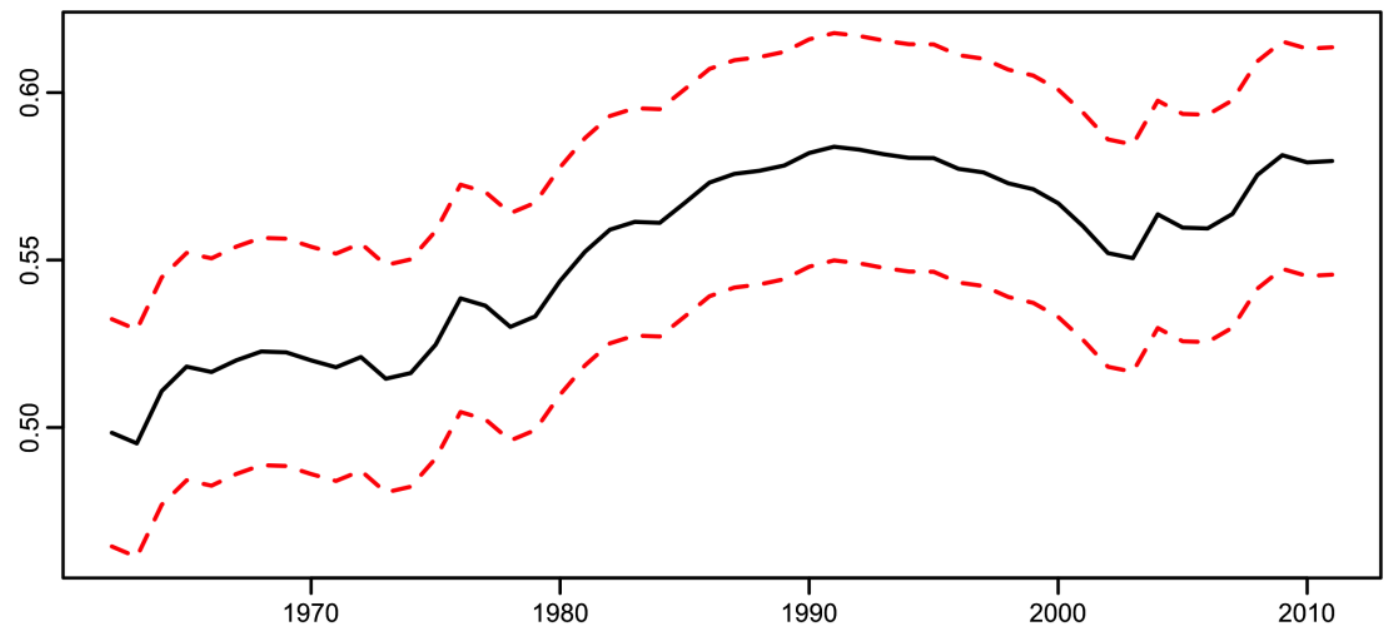

(b) p-value of $H_{0}: \gamma_{2, t}=0$

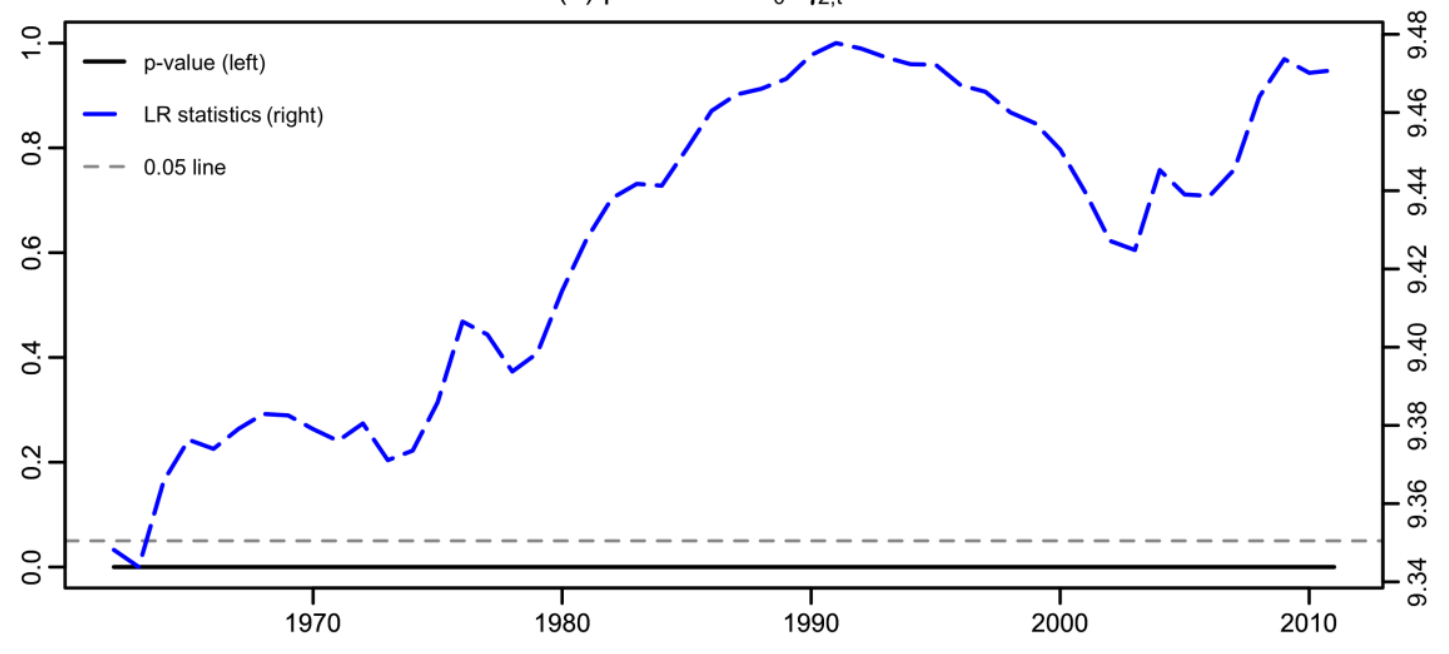

Notes: See notes to Figure 4.

Figures 6 displays the short-run impacts of tourism receipts on GDP and vice versa estimated by the timevarying VECM. The TVP-VECM explicitly models the parameter variation and propagation, using full sample information optimally, unlike rolling and recursive estimation methods that are used as an alternative to model structural changes (Arslanturk et al., 2011). The state-space model also enables exact dating of the shifts in the causal relationship between the series. In this study, the TVP model is estimated with 2,000 bootstrap resample. The bootstrap procedure yields 2,000 bootstrapped estimates of total impact of tourism receipts on GDP $\left(\psi_{T R, t}^{*}\right)$ and GDP on tourism receipts $\left(\psi_{G, t}^{*}\right)$ for each period. In Figure 6, we report means of these total impact estimates, that is $\underset{T R, t}{-{ }^{*}}=\quad{ }_{T R, t}^{*} / 2,000$ and $\underset{G, t}{-*}=\quad{ }_{G, t}^{*} / 2,000$. These are the bootstrap estimates of the time-varying impacts between the series. Figure 6 also reports the 
$95 \%$ bootstrap confidence intervals for the total impact estimates $\bar{\psi}_{T R, t}^{*}$ and $\bar{\psi}_{G, t}^{*}$. We report the mean and 95\% confidence interval estimates of the impact of tourism receipts on GDP in panel A of Figure 6. The plot of $\bar{\psi}_{T R, t}^{*}$ indicates that the sign of the effect from tourism receipt to GDP changed from positive to negative in 1983 and back to positive again in 1990. The negative coefficient is however not significant, except in 1985, coinciding with the declaration of a state of emergency in the country, the debt standstill agreement and the onset of economic sanctions and international isolation.

Figure 6. Estimates of the Short-Run Impacts

(a) Bootstrap estimates of short-run impact of tourism receipts on GDP and 95\% bootstrap bounds

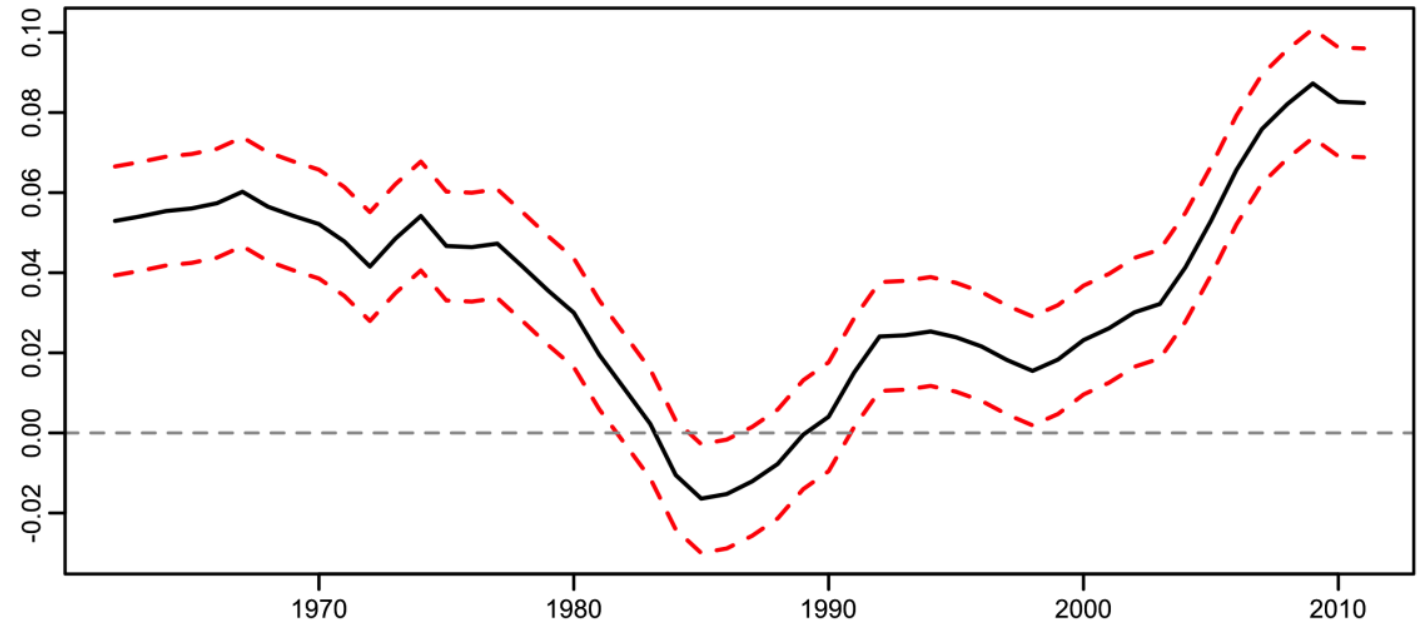

(b) Bootstrap estimates of short-run impact of GDP on tourism receipts and $95 \%$ bootstrap bounds

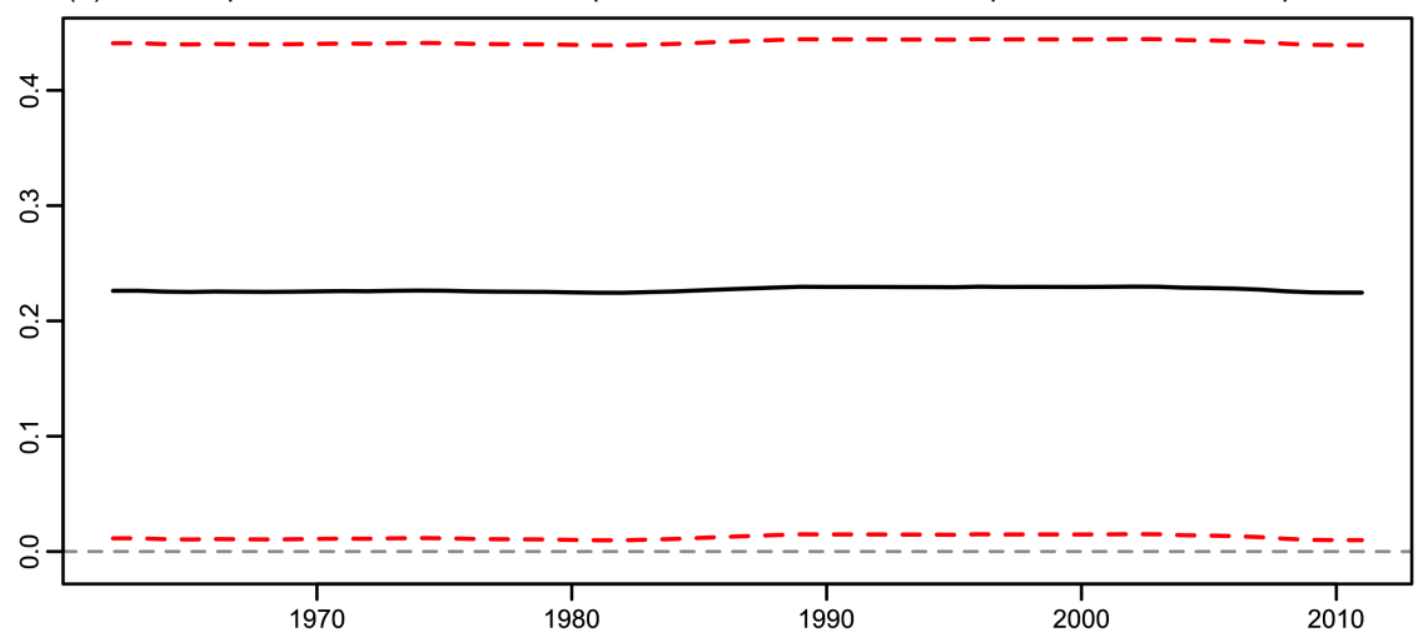

Notes: Parameters are estimated by maximum likelihood of the state-space model. The confidence intervals are constructed using 2000 bootstraps.

The positive impact after 1990 remains positive and significant for the rest of the sample period. This positive impact coincides with the dismantling of Apartheid that started with the release of Nelson Mandela in February 1990, eventually leading to the establishment of a democracy in 1994 and the full opening up 
of the economy to international tourism and trade. The bootstrap estimates of impact of GDP on tourism receipts, $\bar{\psi}_{G, t}^{*}$, are reported in panel B of Figure 6 for each period. The impact of GDP on tourism receipts is estimated as approximately zero for the whole sample period. The $95 \%$ confidence intervals for $\bar{\psi}_{G, t}^{*}$ are marginally over zero and fairly constant, meaning that GDP has predictive content for tourism receipts for the whole sample period we consider. In summary, the TVP model estimates based on the Kalman filter show that there is positive impact from tourism receipts to GDP for the entire sample period, with the exception of the period between 1985 and 1990.

Figure 7. Short-run Granger Causality Tests

(a) p-value of $H_{0}: \phi_{12, t}^{(j)}=0$

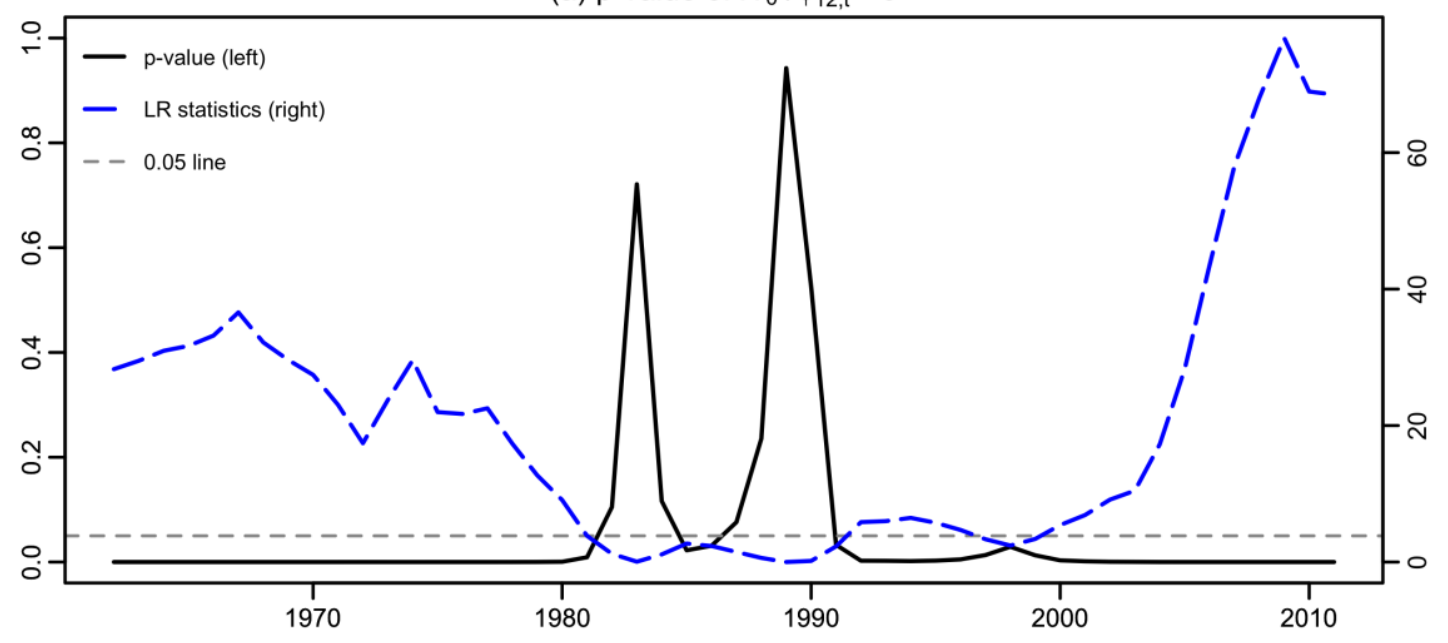

(b) p-value of $H_{0}: \phi_{21, t}^{(j)}=0$

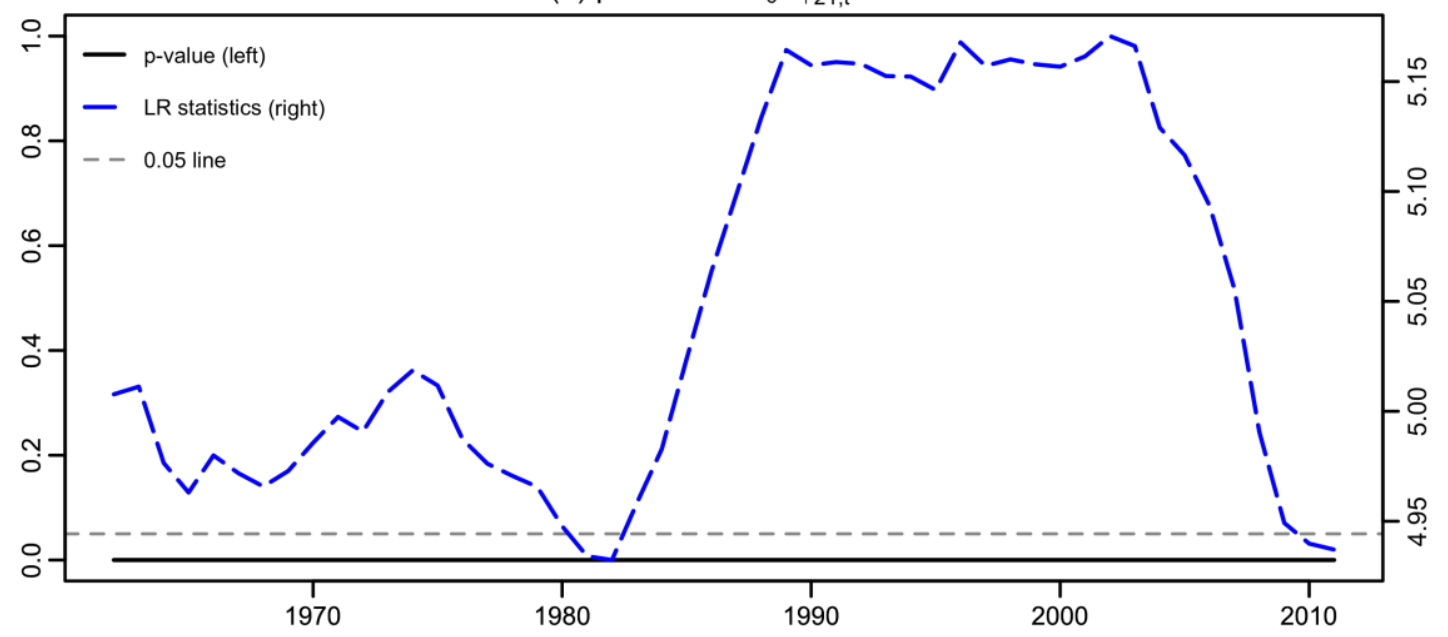

Notes: See notes to Figure 4.

We conclude by reporting $p$-values testing the hypotheses of short-run and strong Granger causality within the time-varying parameter framework. From Figure 7(a) we note that the short-run causal relationship 
between tourism receipts and GDP only breaks down during the 1985-1990 period, the height of the Apartheid regime characterized by cultural and economic sanctions. From Figure 7(b) we marginally reject the null of no Granger causality running from GDP to tourism receipts for the entire period examined.

When considering the time-varying test for the hypotheses of no strong Granger causality, we see in Figure 8 (a) that we reject the null of no Granger causality between tourism receipts and GDP at the 5 per cent level for the entire period examined. Once again the restrictions $\quad \underset{2, t}{ }=0, \quad{ }_{21, t}^{(k)}=0$ are rejected for the entire period, this implies the null of no strong Granger causality from GDP to tourism receipts is rejected.

Figure 8. Strong Causality Tests

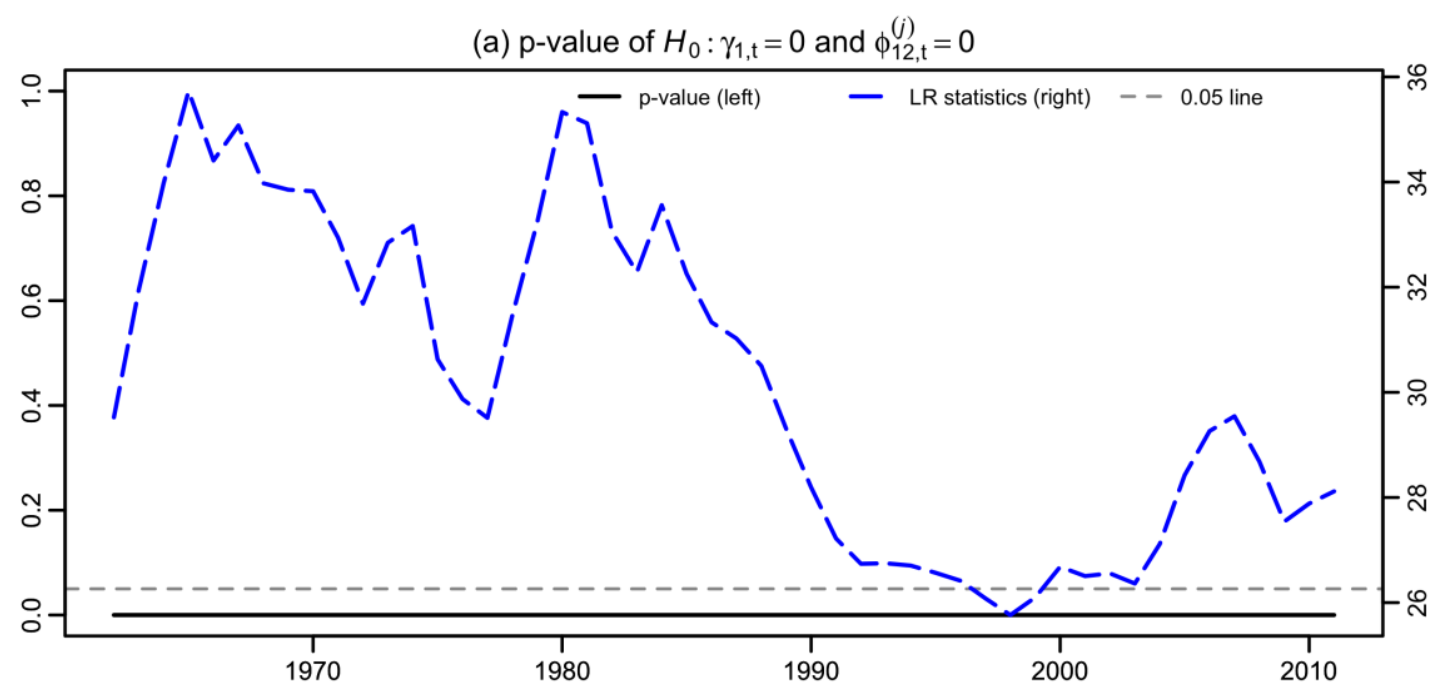

(b) p-value of $H_{0}: \gamma_{2, \mathrm{t}}=0$ and $\phi_{21, \mathrm{t}}^{(j)}=0$

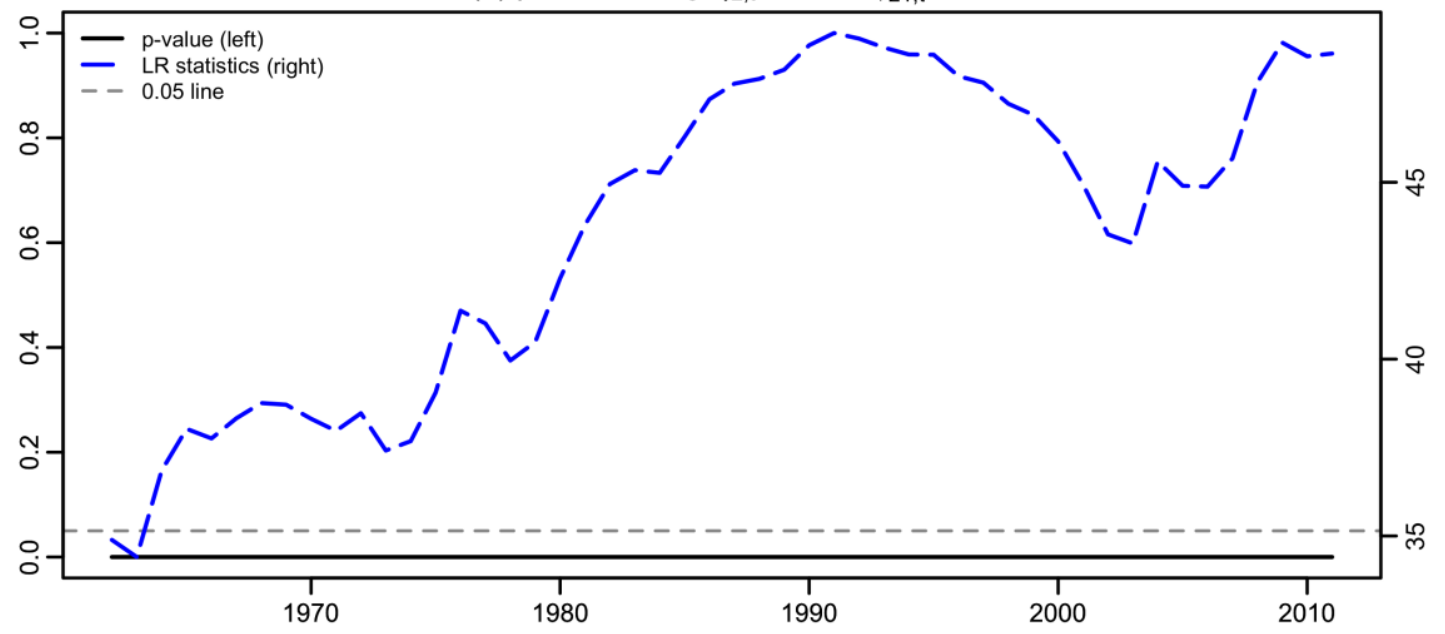

Notes: See notes to Figure 4. 


\section{Conclusion}

This paper investigates the time-varying causal links between the real tourism receipts and real GDP for South Africa by using state-space time-varying coefficients and rolling and recursive window methods for data for covering 1960-2011 period. The methodology employed in this paper allows us to overcome the econometric concerns that could appear in the application of Granger causality tests. Changes in economic policies worldwide as well political and social environment could influence the causality patterns in the data under consideration. For this reason, we prefer to a use time-varying parameter VECM. The empirical analyses yielded the following conclusions: Firstly, the result obtained from the full sample show that there is no Granger causality between tourism receipts and GDP. On the other hand, results obtained from the state-space time-varying coefficients and rolling window estimation methods to analyse the Granger causality based on VECM with time-varying parameters indicate that the tourism receipt positively Granger-causes GDP with a short break in the period between 1985 and 1990 and also GDP haa predictive power for tourism receipts. In terms of the findings obtained from the analyses, it could be held that tourism receipts have a positive impact on the economic growth in South Africa. The result from the statespace time-varying coefficients and rolling window methods draw analogy with the results of Akinboade and Barimoh (2010), Ongan and Demiroz (2005) and Arslanturk, Balcilar and Ozdemir (2011).

\section{References}

Akinboade, O. \& Braimoh, L.A. (2010), International tourism and economic development in South Africa: A Granger causality test, International Journal of Tourism Research, 12, pp. 149-163.

Anderson, B.D.O.; Moore, J.B. (1979). Optimal Filtering, Englewood Cliffs: Prentice-Hall.

Andrews, D.W.K. (1993). Tests for parameter instability and structural change with unknown change point. Econometrica 61(4), 821-856.

Andrews, D.W.K. and Ploberger, W. (1994) Optimal tests when a nuisance parameter is present only under the alternative, Econometrica 62(6): 1383-1414.

Ansley, C.F.; Newbold, P. (1980). Finite sample properties of estimators for autoregressive moving average models, Journal of Econometrics 13, 159-184.

Arslanturk, Y., Balcilar, M. and Ozdemir, Z.A. (2011). Time-varying linkages between tourism receipts and economic growth in a small open economy, Economic Modelling 28: 664-671.

Balaguer, J. \& Cantavella-Jordà, M. (2002), Tourism as a long-run economic growth factor: the Spanish case, Applied Economics, 34, pp. 877-884.

Balassa, B. (1978), Exports and economic growth: Further evidence, Journal of Development Economics, 5, pp. 181-189.

Balassa B. (1988). The Lessons of East Asian Development: an Overview. Economic Development and Cultural Change; 36; 273-290. 
Balcilar, M. Azdemir, Z.A. and Arslanturk, Y. (2013) Economic growth and energy consumption causal nexus viewed through a bootstrap rolling window. Energy Economics 32: 1398-1410.

Belloumi, M. (2010), The relationship between tourism receipts, real effective exchange rate and economic growth in Tunisia, International Journal of Tourism Research, DOI: 10.1002/jtr.774.

Brau, R., Lanza, A. \& Pigliaru, F. (2007), How fast are small tourism countries growing? Evidence from the data for 1980-2003, Tourism Economics, 13(4), pp. 603-613.

Brida, J.G. and Pulina, M. (2010). A Literature review on the Tourism-Led-Growth Hypothesis. Working Paper 2010/17, Centro Ricerche Economiche Nord Sud (Crenos), Universita di Cagliari e Sassari.

Brida, J.G., \& Risso, W.A. (2009), Tourism as a factor of long-run economic growth: An empirical analysis for Chile, European Journal of Tourism Research, 2(2), pp. 178-185.

Brida, J.G., Pereyra, S.J., Risso, W.A., Such Devesa M.J. \& Zapata Aguirrre S. (2009), The tourism-led growth hypothesis: empirical evidence from Colombia, Tourismos: An International Multidisciplinary Journal of Tourism, 4(2) Autumn, pp. 13-27.

Brida, J.G., Lanzilotta, B. \& Risso, W.A. (2008a), Turismo y crecimiento economico: El caso de Uruguay, Pasos, Revista de Turismo y Patrimonio Cultural, 6(3), pp. 481-492.

Brida, J.G., Sanchez Carrrera, E.J. \& Risso, W.A. (2008b), Tourism's Impact on Long-Run Mexican Economic Growth, Economics Bulletin, 3(21), pp. 1-8.

Brohman J. (1996). New Directions in Tourism for Third World Development. Annals of Tourism Research; 23; 48-70.

Cortés-Jimenez, I and Pulina, M. (2010) Inbound tourism and long-run economic growth, Current Issues in Tourism, 13(1), 61-74.

Croes R.R. (2006). A Paradigm Shift to a New Strategy for Small Island Economies: Embracing Demand Side Economics for Value Enhancement and Long Term Economic Stability, Tourism Management; 27; 453-465.

Croes, R. \& Vanegas Sr, M. (2008), Cointegration and causality between tourism and poverty reduction, Journal of Travel Research, 47, August, pp.94-103.

Demiroz, D.M. \& Ongan, S. (2005), The contribution of tourism to the long- run Turkish economic growth, Ekonomický Časopis, 9, pp. 880-894.

Dent, W.T. and Min, A.S. (1978). A Monte Carlo study of autoregressive integrated moving average processes, Journal of Econometrics 7, 7: 23-55.

Dieke, U.C. (2000). Developing tourism in Africa: issues for policy consideration. The Development Policy management forum, 7: 25-31.

Doran, H.E., (1992). Constraining Kalman Filter and Smoothing Estimates to Satisfy Time-Varying, The Review of Economics and Statistics, Vol. 74, No. 3, pp. 568-572.

Dritsakis, N. (2004). Tourism as a long-run economic growth factor: An empirical investigation for Greece using a causality analysis. Tourism Economics 10: 305-316.

Durbarry, R. (2004). Tourism and Economic Growth: the Case of Mauritius. Tourism Economics 10: 389401.

Durbin, J. and Koopman S.J., (2001). Time Series Analysis by State-space Methods, New York: Oxford University Press, 2001. 
Efron, G. (1979). Bootstrap Methods: Another Look at the Jackknife, The Annals of Statistics; 7, 1-26.

Engle, R.F. \& Granger, C.W.J. (1987), Cointegration and error correction: representation, estimation and testing, Econometrica, 55, pp. 251-276. Feder, G. (1983) On exports and economic growth, Journal of Development Economics, 12, pp. 59-73.

Eugenio-Martín, J.L., Morales, N.M. and Scarpa, R. (2004) Tourism and Economic Growth in Latin American Countries: A Panel Data Approach, Working Papers 2004.26, Fondazione Eni Enrico Mattei, Milan, Italy.

Gunduz L. and Hatemi-J A. (2005). Is the tourism-led growth hypothesis valid for Turkey? Applied Economics Letters 12: 499-504.

Ghatak S, Milner C. and Utkulu U. (1997). Exports, Export Composition and Growth: Cointegration and Causality Evidence for Malaysia. Applied Economics 29: 213-223.

Granger, C.W.J. (1969) Investigating causal relations by econometric models and cross spectral methods. Econometrica 37: 424-438.

Granger, C.W.J. (1988), Causality, cointegration and control, Journal of Economic Dynamics and Control, 12 , pp. 551-559.

Hall, S.G., Hondroyiannis, G., Swamy, P.A.V.B. and Tavlas, G.S. (2009). Assessing the causal relationship between euro-area money and prices in a time-varying environment, Economic Modelling, $26,760-766$.

Hall, S.G. Hondroyiannis, G., Swamy, P.A.V.B. and Tavlas, G.S. (2010) The Fisher Effect Puzzle: A Case of Non-Linear Relationship?, Open Economies Review, 21: 91-103.

Hansen, B.E. (1992a) Testing for parameter instability in linear models. Journal of Policy Modelling 14, 517-533.

Hansen, B.E. (1992b) Tests for parameter instability in regressions with I(1) processes. Journal of Business and Economic Statistics 10. 321-336.

Hazari B.R. and Ng A. (1993). An analysis of tourists' consumption of non-traded goods and services on the welfare of the domestic consumers. International Review of Economics and Finance 2: 3-58.

Hurvich, C. M. \& Tsai, C.-L. (1989). Regression and Time Series Model Selection in Small Samples. Biometrika, 76, 297-307.

Johansen S. (1991). Estimation and hypothesis testing of cointegration vectors in Gaussian vector autoregressive models. Econometrica 59: 1551-1580.

Katircioglu, S.T. (2009a), Tourism, trade and growth: the case of Cyprus, Applied Economics, 41, pp. 2741-2750.

Katircioglu, S.T. (2009b), Testing the tourism-led growth hypothesis: The case of Malta, Acta Oeconomica, 59(3), pp. 331-343.

Katircioglu, S.T., (2009c), Revising the tourism-led-growth hypothesis for Turkey using the bounds test and Johansen approach for cointegration, Tourism Management, 30, pp. 17-20.

Kim HJ, Chen M.H. and Jang S.C. (2006). Tourism expansion and economic development: The case of Taiwan. Tourism Management 27; 925-933.

Koutris, A. Heracleous, M.S. and Spanos, A.(2008). Testing for non-stationarity using maximum entropy resampling: A misspecification perspective. Econometric Reviews 27, 363-384. 
Kuan, C.M. and Chen, M.Y. (1994) Implementing the fluctuation and moving-estimates tests in dynamic econometric models. Economics Letters 44(3), 235-239.

Lean, H.H. \& Tang, C.F. (2009), Is the tourism-led growth hypothesis stable for Malaysia? A note, International Journal of Tourism Research, 12(4), pp. 375-378.

Nayaran, P.K., Nayaran, S., Prasad, A. \& Prasad, B.C. (2010)Tourism, and economic growth: a panel data analysis for Pacific Island countries, Tourism Economics, 16(1):169-183.

Ng, S. and Perron, P. (2001) Lag length selection and the construction of unir toor tests with good size and power, Econometrica 69, 1519-1554.

Nowak, J-J., Sahli, M. \& Cortés-Jiménez, I. (2007), Tourism, capital good imports and economic growth: theory and evidence for Spain, Tourism Economics, 13(4), pp. 515-536.

Nyblom, J. (1989). Testing for the constancy of parameters over time. Journal of the American Statistical Association 84(405), 223-230.

Lee C-C. and Chang C.-P. (2008). Tourism development and economic growth: A closer look at panels. Tourism Management 29: 180-192.

Oh C.O. (2005). The contribution of tourism development to economic growth in the Korean economy. Tourism Management 26: 39-44.

Ongan S, Demiroz D.M. (2005). The contribution of tourism to the long-run Turkish economic growth. Ekonomicky' c'asopis. [Journal of Economics] 53: 880-894.

Osterwald-Lenum M. (1992). A note with fractiles of the asymptotic distribution of the maximum likelihood cointegration rank test statistics: four cases. Oxford Bulletin of Economics and Statistics 54: 461-472.

Pedroni, P. (2004) Panel Cointegration: Asymptotic and Finite Sample Properties of Pooled Time Series Tests with an Application to the PPP Hypothesis, Economic Theory, Cambridge University Press, 20(03), 597-625, June.

Pesaran, H.M., Shin, Y. \& Smith, R.J. (2001), Bounds testing approaches to the analysis of level relationships, Journal of Applied Econometrics, 16, pp. 289-326.

Pesaran, M.H. and Timmerman, A. (2005) Small sample properties of forecasts from autoregressive models under structural breaks. Journal of Econometrics 129, 183-217.

Phillips, P.C.B. and Hansen, B.E. (1990). Statistical inference in instrumental variables regression with I(1) processes. Review of Economics Studies 57, 99-125.

Saayman, A. and Saayman, M. (2008) Determinants of inbound tourism to South Africa, Tourism Economics, 14(1), 81-96.

Said, S. and Dickey D.A. (1984). Testing for unit roots in autoregressive-moving average models of unknown order. Biometrika 71: 599-607.

Salman, A.K. and Shukur, G. (2004) Testing for Granger causality between industrial output and CPI in the presence of regime shift: Swedish data, Journal of Economic Studies 01/2004, 31 (October); 492-499.

Schubert, F.S., Brida, J.G. \& Risso, W.A. (2010) The impacts of international Tourism demand on economic growth of small economies dependent of tourism, Tourism Management, doi:10.1016/j.tourman.2010.03.007.

Shumway, R.H. and Stoffer, D.S. (2000). Time Series Analysis and Its Applications. New York: Springer. 
Stock, J. and Watson, M.W. (1993) A Simple Estimator of Cointegrating Vectors in Higher Order Integrated Systems, Econometrica, Econometric Society, 61(4), 783-820, July.

Stoffer, D.S. and Wall, K. (1991). Bootstrapping state-space models: Gaussian maximum likelihood estimation and the Kalman filter, Journal of the American Statistical Association 86: 1024 - 1033.

Theobald W.F. (2001). Global Tourism, Oxford: Butterworth \& Heinemann, Second Edition, 2001.

UNWTO (2010) International Recommendations for Tourism Statistics 2008, UN DESA and UNWTO, New York.

UNWTO (2013) Tourism Highlights, 2013 Edition. United Nations World Tourism Organisation, New York.

Vanegas M, Croes R.R. (2003). Growth, Development and Tourism in a Small Economy: Evidence from Aruba. The International Journal of Tourism Research 5; September/October: 315-330. 